\title{
Choice set dependent performance and post-decision dissonance $^{\text {is }}$
}

\author{
Toru Suzuki \\ University of Technology Sydney, Broadway NSW 2007, PO Box 123, Australia
}

\section{A R T I C L E I N F O}

\section{Article history:}

Received 14 November 2018

Revised 26 February 2019

Accepted 23 April 2019

\section{JEL classification:}

D83

D91

\section{Keywords:}

Choice set-dependence

Post-decision dissonance

Optimal choice set design

\begin{abstract}
A B S T R A C T
A decision maker (DM) selects a project from a set of alternatives with uncertain productivity. After the choice, she observes a signal about productivity and decides how much effort to put in. This paper analyzes the optimal decision problem of the DM who rationally filters information to deal with her post-decision cognitive dissonance. It is shown that the optimal effort level for a project can be affected by unchosen projects in her choice set, and the nature of the choice set-dependence is determined by the signal structure. Some comparative statics of choice set-dependence is also provided. Finally, based on the results, the optimal choice set design is also explored. This paper offers a simple framework to explain the experimental finding in psychology that people's effort level for a project can be enhanced when the project is chosen by themselves rather than by others.
\end{abstract}

(c) 2019 Elsevier B.V. All rights reserved.

"Many are stubborn in pursuit of the path they have chosen, few in pursuit of the goal."

Friedrich Nietzsche

\section{Introduction}

Casual observation suggests that people tend to make a more persistent effort for a project when it is chosen by themselves rather than by others. In fact, there is considerable experimental evidence that providing an opportunity of choice could boost people's persistence of effort for a project compared to the case in which the same project is assigned by others, e.g., Zuckerman et al. (1978), Cordova and Lepper (1996), and Iyengar and Lepper (1999). There are at least two reasons for economists to investigate such a choice provision effect. First, if a decision maker (DM) is the standard rational agent, her effort choice for the same project should not depend on whether it is chosen by herself or assigned by others. If the effort choice for the same project depends on the presence of unchosen options, the DM's effort level exhibits novel choice setdependence. Second, understanding the choice provision effect on performance can expand the domain of incentive theory; one could design a choice set to manage the effort level of workers or students by utilizing the choice set-dependence of their effort level. The purpose of this paper is to provide a simple model to analyze such a choice set-dependent performance and explore the optimal choice provision problem.

The key premise of this paper is that a DM could suffer from post-decision dissonance; when the DM observes a signal that does not support her choice, she could experience unpleasant feeling and suppress the information. The current paper

\footnotetext{
诂 I am grateful to three anonymous referees and the associate editor for helpful suggestions. I also appreciate useful comments from Itzhak Gilboa, Bart Lipman, the seminar and workshop participants at Monash University and China GBA workshop.

E-mail address: toru.suzuki@uts.edu.au
} 
demonstrates that, while the choice provision effect is not usually explained by post-decision dissonance in the psychological literature, once post-decision dissonance is carefully formulated, the choice provision effect can be explained as a natural consequence of post-choice dissonance. The basic idea of the paper is based on the following observation: when there is no choice, the DM has no room to experience post-decision dissonance as her choice cannot be "wrong" and no reason to ignore new information in the post-choice stage; in contrast, when a project is chosen from some options, the DM could experience post-choice dissonance since her choice could turn out to be ex-post inferior to other options. Consequently, when an opportunity of choice is provided, she has an incentive to neglect dissonant information, and her belief about the productivity of the chosen project could be distorted; notably, the information suppression could boost her effort level when the dissonant information is negative compared to having no information. The current paper provides a formal framework to capture the above idea and clarifies how the structure of signals and the size/composition of a choice set could affect the DM's output. The optimal choice set that maximizes the DM's performance is also explored.

The current paper analyzes the choice set-dependent performance in a simple two-stage decision problem. The DM makes a choice from a set of feasible projects with uncertain productivity. After she chooses a project, she observes a signal that is correlated with the productivity of each project. The central assumption is that when the DM observes a signal that does not support her project choice, the signal reduces her utility because of post-decision dissonance. The DM then optimally chooses whether to suppress a dissonant signal to manage the unpleasant feeling at the cost of a suboptimal effort level induced by the information suppression. In short, the DM in this paper optimally deals with the two-stage decision problem under her psychological constraint.

Since the effect of dissonance depends on the signal structure in general, this paper categorizes dissonance signals, i.e., a signal that does not support a chosen project, into two types: when a dissonant signal reduces the expected utility from a chosen project, the dissonant signal is regular; if a dissonant signal increases the expected utility from a chosen project but the signal makes the expected utility from some other projects even higher than that from the chosen project, the dissonant signal is non-regular. It is shown that when the dissonant signal is regular, the provision of choice could improve the DM's performance, whereas the provision of choice could decrease the DM's performance when a dissonant signal is non-regular. The idea behind this dissonance effect is simple. When a dissonant signal is regular, it is a negative signal for the chosen project. Thus, suppressing the signal makes her belief about the productivity of the chosen project more optimistic than the unbiased belief. As a result, this self-justification boosts her effort level. On the contrary, when a dissonant signal is nonregular, it is a positive signal for the productivity of the chosen project. Consequently, the DM's self-justification reduces her effort level as she ignores the positive signal. Unlike in the effect of dissonance on the effort choice, the effect of dissonance on the DM's utility does not depend on the signal structure; the provision of choice never improves the DM's utility since a dissonant signal creates discomfort whenever she does not suppress the signal, whereas the dissonant signal induces a suboptimal effort choice whenever she neglects it.

The main result of this paper is on the choice set-dependent performance. It is shown that if all dissonant signals are regular, the expected output of a project chosen from some choice set is weakly higher than that of the same project chosen from a smaller choice set. The reasoning behind the result is as follows. Under a larger choice set, the set of dissonant signals also becomes larger. Since the cost of signal-suppression is determined by the distortion generated by the uninformed decision, the cost of suppression is independent of a choice set. Hence, whenever the DM optimally suppresses a dissonant signal under some choice set, it is also optimal for her to suppress the same signal under a larger choice set. Then, since the set of optimally suppressed dissonant signals is larger under a larger choice set, the expected effort level has to be weakly higher under a larger choice set if all dissonant signals are regular. In the discussion section, it is shown that this main result is preserved under mild assumptions even if we consider a general information processing rule in which the DM can distort her perception of a received signal in addition to suppression. The effect of a larger choice set on the DM's utility is opposite: since a larger choice set weakly increases the chance of experiencing dissonance, the DM's utility from a project chosen from a small choice set is never lower than that from the same project chosen from a larger choice set.

This paper also provides the comparative statics analysis on how the composition of choice set could affect the DM's utility and performance. To obtain a clear-cut result, I focus on a class of signal structures in which signals are only about a chosen project, i.e., project-specific signals. It is found that if signals are project-specific, the expected output from a project that is chosen from a choice set with attractive alternatives is higher than that is chosen from a choice set with unattractive alternatives. The intuition behind the result is as follows: when signals are project-specific, the ex-ante second most attractive choice determines whether a signal is dissonant or not. Thus, whenever a choice set includes an attractive alternative, the DM has a larger set of dissonant signals that could be suppressed. Then, the choice set with an attractive alternative generates more dissonance and boosts the DM's effort level more than that with unattractive alternatives. It is also shown that the effect of an attractive alternative on the DM's utility is the opposite; since a choice set with an attractive alternative could expand that the set of dissonant signals, the DM's utility from a project that is chosen from attractive alternatives is lower than that is chosen from unattractive alternatives.

Based on the results of the choice set-dependent performance, this paper also explores the optimal choice provision problem; how can a manager or a teacher design a choice set if they wish to maximize the performance of a worker or a student? First, when the designer wishes to maximize the DM's utility, the optimal choice set can be found quite easily; it is optimal to provide the best project without any alternative so that the DM does not need to suffer from postdecision dissonance. On the contrary, when the designer wishes to maximize the DM's output, the optimal choice provision problem becomes much delicate. From the earlier analysis, given a project, the expected output level from the project can 
be increased by providing more choices. However, since adding less attractive projects could affect the DM's project choice through dissonance aversion, the designer needs to take into account "choice-compatibility" of the most productive project. Consequently, the feasible set, i.e., the largest choice set, is not always an output maximizing choice set. I then provide the condition under which the largest choice set is an output maximizing choice set.

The overview of the rest of this paper is as follows: after the literature review, Section 2 presents the basic setting and analyzes the standard rational decision making as a benchmark. In Section 3, the concept of post-decision dissonance is formalized, and the model of decision under dissonance is introduced. Section 4 analyzes the optimal decision under dissonance and provides some results on choice-set dependent performances. The optimal choice set is investigated in Section 5. Some discussions are presented in Section 6 followed by concluding remarks.

Related literature. The current paper is motivated by the finding in psychology that the provision of choice could enhance one's motivation, especially persistence, for a chosen task. For example, Zuckerman et al. (1978) found that participants who were asked to choose spatial relation puzzles from options spent more time engaged in the puzzle-solving task compared to participants who were assigned to work on the same puzzles; Iyengar and Lepper (1999) found that students performed better when they made personal choices about which tasks to work on rather than specifying tasks. ${ }^{1}$ Cordova and Lepper (1996) found that children provided with choices demonstrated greater learning, as measured by the number of problems answered correctly on a math test after the session.

When adding chosen alternatives could enhance the DM's effort level for the same project, her behavior exhibits choice set-dependence. Arguably the most well-known choice set-dependence is "reason-based choice," i.e., attraction and compromise effects, reported by Huber et al. (1982), Simonson (1989), and Shafir et al. (1993). In the reason-based choice literature, the presence of a dominated choice affects the choice outcome since a decision maker could compare options with multiple aspects differently when a dominated choice is added to her choice set. Several models have been proposed to explain this effect in economics, e.g., Lombardi (2009), De Clippel and Eliaz (2012), and Ok et al. (2015). The choice set-dependence in the current paper is different from the reason-based choice literature in two aspects; first, the main choice set-dependence in the current paper is in the DM's effort level rather than in her project choice; adding an unchosen project in her choice set could affect her effort level for the same project. Second, unlike in the reason-based choice models, the choice setdependence in the current paper is not caused by the difficulty of multi-aspect comparison, but the choice set-dependence of post-decision dissonance.

Another type of choice set-dependence can be found in anticipated regret models introduced by Bell (1982) and Loomes and Sugden (1982). In their models, the DM's project choice can be affected by an unchosen project since the degree of ex-post regret could depend on the unchosen project. Since post-decision dissonance can be interpreted as "interim regret," the project choice part of the current model could exhibit choice set-dependence that is reminiscent of that in anticipated regret models. However, the primary interest of the current paper is in the choice set-dependence of the effort level rather than the project choice; the DM's effort level for a project chosen from a set of projects can be different from the effort level for the same project chosen from a different set of projects. As it is shown in Section 6, when the standard anticipated regret model is applied to the project-effort choice problem in the current paper, the regret model does not produce such a choice set-dependent effort level. Thus, the post-decision dissonance model in the current paper generates a new type of choice set-dependence, which is motivated by the choice provision effect.

The central assumption of the current paper is that the DM experiences cognitive dissonance and optimally deals with it. Since Festinger (1957), there has been ample evidence that when people recognize their inconsistency between beliefs, attitudes, and actions, they experience dissonance and try to reduce dissonance by adjusting one of the controllable dissonant factors such as their perception. Since the decision problem in the current paper has the project choice stage, this paper considers post-decision dissonance, which is the most typical dissonance in the context of free-choice. ${ }^{2}$ Brehm (1956) demonstrated that choosing between alternatives could create dissonance, and people attempted to reduce dissonance by perceiving the chosen alternative more desirable and the unchosen alternative less desirable. Lawler III et al. (1975) observed that the attractiveness of accepted jobs tend to increase whereas that of a rejected job decreases after a job is chosen. Mills (1965) found that people tend to avoid dissonant information suggesting that selective perception contributes to their attitude change. In economics, some fruitful applications of cognitive dissonance have been reported. For instance, Akerlof and Dickens (1982) showed that workers in hazardous occupations could underinvest in safety equipment if they underestimate the risk as a result of cognitive dissonance; Rabin (1994) shows that immoral activities can be enhanced by cognitive dissonance; Konow (2000) demonstrates that cognitive dissonance affects people's attitude toward fair allocation.

The role of cognitive dissonance in the current paper is closest to that in the phenomenon called escalation of commitment; Staw (1976) found that subjects tend to continue investing in a poorly performing project when they personally feel responsible about negative outcomes of the project. He then explained his experimental finding as a consequence of postdecision dissonance. Some economists provided models of escalation of commitment based on post-decision dissonance. Eyster (2002) analyzes a DM with a taste for rationalizing her past choices through current choices. In his model, the DM initially chooses an action under uncertainty, which is resolved in the next period. However, since the DM's utility depends

\footnotetext{
${ }^{1}$ One might wonder that if subjects could select their favorite puzzles from options, their persistence would be a natural consequence. However, in Zuckerman et al. (1978) and Iyengar and Lepper (1999), their set of puzzles consists of the same type of puzzles, and there is no reason to believe that one puzzle could look more attractive or easier than others at their choice stage.

${ }^{2}$ Post-decision dissonance is also called "dissonance from free choice" or "dissonance after decisions" in some social psychology textbooks.
} 
on not only the material outcome but also the consistency between his first and second actions, the DM's second decision could be chosen so that it confirms the first action. In Yariv (2002), the preference for consistency is modeled as the disutility from changing one's belief. The DM then chooses her posterior belief to balance the psychological benefit of her biased belief and the cost of her suboptimal decision induced by the distortion. Consequently, the DM tends to exhibit confirmatory bias and chooses an action that supports her initial decision. The model in the current paper is closer to Yariv (2002) than Eyster (2002) since, as in Yariv (2002), the DM in the current paper deals with dissonance by controlling her perception rather than her action; that is, the biased action is a consequence of her biased perception. The difference between the current paper and Yariv (2002) is that the DM experiences discomfort from a change of belief in her model, whereas the DM experiences discomfort from a signal that does not support her project choice, i.e., dissonant signal, in the current paper. Consequently, whether our DM dislikes a signal or not depends not only on the informational content but also on the context of the signal, that is, a signal can be dissonant under some choice set but the same signal can be consonant under a different choice set. By formalizing the context sensitivity of dissonance, the current model can analyze how a choice set could affect the DM's performance given a signal structure.

Finally, since the current paper analyzes the design of a choice set that manages the DM's effort level, the current paper also contributes to the literature on non-standard incentives. Gneezy and Rustichini (2000) found that the monetary reward could crowd out people's motivation; Benabou and Tirole (2003) provide a model of the crowding out effect based on an informed principal model. Falk and Kosfeld (2006) found that imposing a minimal investment restriction reduced the investment level in their experiment, suggesting that the sense of distrust could discourage investments. Charness et al. (2012) report that delegating the wage choice to employees significantly increases effort levels in their experiment. Suzuki (2017) shows the principal's message that suggests the optimal action to the agent could undermine the agent's effort level in the equilibrium when the message conveys the principal's distrust as the secondary meaning of the message.

\section{Setting}

\subsection{Basics}

A decision maker (DM) chooses a project $x$ from a set of alternatives $X$, which is finite. The output of the project $x$ is determined by her effort level $e \in E=[\underline{e}, \bar{e}]$ and the productivity of the project $\theta_{x} \in \Theta$ where $\Theta$ is a finite set. ${ }^{3}$ Specifically, the output $y \in Y=[0, \infty)$ is determined by a function $f: E \times \Theta \rightarrow Y$ such that, given any $\theta_{x} \in \Theta, f\left(\underline{e}, \theta_{x}\right)=0, f_{e}\left(e, \theta_{x}\right)>0$ and $f_{e e}\left(e, \theta_{x}\right) \leq 0$ for all $e \in E$. Moreover, assume that if $\theta_{x}^{\prime}<\theta_{x}^{\prime \prime}$, then $f_{e}\left(e, \theta_{x}^{\prime}\right)<f_{e}\left(e, \theta_{x}^{\prime \prime}\right)$ for all $e \in E$. The DM's cost from her effort $e$ is determined by a function $c: E \rightarrow[0, \infty)$, which is strictly convex, i.e., $c_{e}(e)>0$ and $c_{e e}(e)>0$ for all $e \in E$.

The DM cannot observe the productivity of any project. However, when she chooses a project $x$ from her choice set $X$, the DM observes a signal $s_{X} \in S_{X}$ where $S_{X}$ is a finite set. The signal can be new information that is specific to the chosen project such as detailed technical facts about the project or some general information that is relevant to the productivity of all projects, e.g., news about the current economic condition. Then, let $g(\boldsymbol{\theta}, \boldsymbol{s})$ be the joint probability distribution of $\boldsymbol{\theta}=\left(\theta_{x}\right)_{x \in X}$ and $\boldsymbol{s}=\left(s_{X}\right)_{x \in X}$. Assume that $\boldsymbol{s}$ is conditionally independent given $\boldsymbol{\theta}$. That is, a signal $s_{X^{\prime}}$ can be correlated with the productivity of any project $x \in X$, whereas $s_{X}$ and $s_{x^{\prime}}$ are independent given $\boldsymbol{\theta}$ if $x \neq x^{\prime}$.

It is assumed that, for any $x, S_{X}$ includes "no news," which is signified by $\varnothing .{ }^{4}$ Moreover, for any $s_{X} \neq \varnothing$, conditional probability functions $p\left(\theta_{x} \mid \varnothing\right)$ and $p\left(\theta_{x} \mid s_{x}\right)$ are strictly ranked in terms of first-order-stochastic dominance. In other words, for any $x$, any signal $s_{x} \neq \varnothing$ is either good or bad news compared to no news $\varnothing$. Furthermore, assume that $\varnothing$ has no information about $\theta_{x}$, i.e., given any $x, p\left(\theta_{x}\right)=p\left(\theta_{x} \mid \varnothing\right)$. This assumption can be interpreted that whether the DM receives some news or not is determined by an exogenous factor that does not depend on productivity.

When the DM produces the output $y$ with her effort level $e$, her utility is given by $y-c(e)$. To guarantee the interior solution, assume that

$$
\min _{\theta_{x} \in \Theta} f_{e}\left(\underline{e}, \theta_{x}\right)-c_{e}(\underline{e})>0>\max _{\theta_{x} \in \Theta} f_{e}\left(\bar{e}, \theta_{x}\right)-c_{e}(\bar{e}) .
$$

The timeline of the model is as follows: the DM chooses a project $x$ from a choice set $X$; after the choice, she receives a signal $s_{X}$ for the chosen project; she then chooses how much effort to put into the project; finally, the outcome is determined.

\subsection{Benchmark analysis}

Before introducing the key element into the model, I briefly describe how the standard rational DM makes optimal decisions. Suppose that the DM chooses project $x$. If she observes $s_{x}$, she forms her expectation about $\theta_{x}$ and solves the following problem.

\footnotetext{
${ }^{3}$ One can also interpret $\theta_{x}$ as the enjoyability of project $x$

4 "No news" plays an important role in the next section.
} 


$$
\max _{e \in E}\left\{\sum_{\theta_{x}} f\left(e, \theta_{x}\right) p\left(\theta_{x} \mid s_{x}\right)-c(e)\right\} .
$$

Let $e_{x}^{*}\left(s_{X}\right)$ be the optimal effort level given $s_{x}$. Then, the expected utility from project $x$ is

$$
\left.U(x)=\sum_{s_{x} \in S_{x}} \sum_{\theta_{x} \in \Theta}\left[f\left(e_{x}^{*}\left(s_{x}\right), \theta_{x}\right)\right)-c\left(e_{x}^{*}\left(s_{x}\right)\right)\right] p\left(s_{x}, \theta_{x}\right)
$$

The DM's optimal project choice is then the solution of $\max _{x \in X} U(x)$.

\section{A model of post-decision dissonance and optimal decisions}

This section introduces the concept of post-decision cognitive dissonance and formalizes the optimal decision making under dissonance. I then analyze some properties of the optimal decision rules and choice set-dependence.

\subsection{Post-decision dissonance}

Cognitive dissonance is unpleasant feeling aroused by inconsistency between one's action, belief and attitude. One of the typical situations in which people experience dissonance is post-decision; when people perceive information that does not support their choices, the sense of inconsistency could arouse discomfort, and they often reduce dissonance by controlling their perception. That is, the process of post-decision dissonance consists of two stages: arousal and reduction.

To formalize the arousal of post-decision dissonance, let

$$
U\left(x \mid s_{X}\right)=\sum_{\theta_{x}}\left[f\left(e_{x}^{*}\left(s_{x}\right), \theta_{x}\right)-c\left(e_{x}^{*}\left(s_{x}\right)\right)\right] p\left(\theta_{x} \mid s_{X}\right)
$$

that is, this is the expected utility from project $x$ given $s_{X}$. Suppose that the DM selects $x$ from $X$. Then, a signal $s_{X} \neq \varnothing$ is consonant if the expected utility from $x$ conditional on $s_{X}$ is equal to or higher than that from any project in $X$ conditional on $s_{x}$, i.e., $U\left(x^{\prime} \mid s_{x}\right) \leq U\left(x \mid s_{X}\right)$ for all $x^{\prime} \in X$. On the other hand, a signal $s_{x} \neq \varnothing$ is dissonant if the expected utility from $x$ conditional on $s_{X}$ is lower than that from some project in $X$ conditional on $s_{X}$, i.e., $U\left(x^{\prime} \mid s_{X}\right)>U\left(x \mid s_{X}\right)$ for some $x^{\prime} \in X$. Then, given $x$ and $X$, the set of dissonant signals is defined by

$$
S_{x}^{d}(X)=\left\{s_{x} \in S_{x} \backslash\{\varnothing\}: \exists x^{\prime} \in X \text { s.t. } U\left(x^{\prime} \mid s_{X}\right)>U\left(x \mid s_{X}\right)\right\} .
$$

The above formulation of dissonant signals captures the essential nature of dissonance, that is, whether a signal is consonant or dissonant depends on the context of the signal; a signal can be dissonant if there is an alternative that becomes more attractive than the chosen project, whereas the same signal is consonant if there is no such alternative. ${ }^{5}$ One of the notable properties is that if $X=\{x\}$, then $S_{x}^{d}(X)=\emptyset$. That is, if there is no opportunity of choice, there is no signal that creates post-decision cognitive dissonance.

The DM experiences post-decision dissonance if a signal $s_{X}$ is dissonant, i.e., $s_{X} \in S_{X}^{d}(X)$, whereas she experiences no dissonance if $s_{X} \notin S_{X}^{d}(X)$. Formally, the dissonance level from $s_{X}$ is determined by a real valued function $\gamma_{X}\left(s_{X} ; X\right)$ such that $\gamma_{X}\left(s_{X} ; X\right)>0$ if $s_{X} \in S_{X}^{d}(X) ; \gamma_{x}\left(s_{x} ; X\right)=0$ if $s_{X} \notin S_{X}^{d}(X)$. Moreover, it is assumed that $\gamma_{X}\left(s_{x} ; X\right) \leq \gamma_{X}\left(s_{X} ; X^{\prime}\right)$ if $X \subset X^{\prime}$ and $s_{X} \in$ $S_{x}^{d}(X) \cap S_{x}^{d}\left(X^{\prime}\right)$. That is, given a choice $x$, adding some options to a choice set cannot reduce the level of dissonance form a dissonant signal $s_{x}$. There are numerous specifications of $\gamma_{x}$ that satisfy the above properties. The first example describes the DM who is only bothered by the fact that her choice is not optimal given $s_{x}$.

Example 1. $\gamma_{X}\left(s_{X} ; X\right)=k>0$ if $s_{X} \in S_{X}^{d}(X)$.

In the next example, the DM's degree of dissonance is increasing in her degree of "interim regret." This functional form can also be found in the anticipated ex-post regret model of Sarver (2008).

Example 2. $\gamma_{x}\left(s_{x} ; X\right)=\alpha\left[\max _{x^{\prime} \in X} U\left(x^{\prime} \mid s_{X}\right)-U\left(x \mid s_{X}\right)\right]$ where $\alpha>0$.

In the following example, the DM's dissonance level is determined by the number of choices that are better than her choice after observing a signal.

Example 3. $\gamma_{x}\left(s_{x} ; X\right)=r\left(\#\left\{x^{\prime} \in X: U\left(x^{\prime} \mid s_{x}\right)>U\left(x \mid s_{x}\right)\right\}\right)$ where $r($.$) is an increasing function with r(0)=0$.

Since post-decision dissonance is unpleasant, it reduces the DM's utility. Thus, suppose that when the DM selects $x$ from $X$, her utility from the output $y$ and her effort $e$ given a signal $s_{x}$ is

$$
y-c(e)-\gamma_{x}\left(s_{x} ; X\right) \text {. }
$$

The second step of cognitive dissonance is dissonance reduction; when a choice creates dissonance but the choice is (essentially) irreversible, people tend to reduce dissonance by controlling their perception. The basic model of this paper

\footnotetext{
${ }^{5}$ This is contrary to the consistency aversion model by Yariv (2002) in which the DM experiences discomfort whenever her belief changes.
} 
considers one of common ways to handle dissonance. ${ }^{6}$ Specifically, when the DM receives $s_{X} \neq \varnothing$, she can choose whether to suppress $s_{X}$ in order to eliminate dissonance. ${ }^{7}$ To formalize the idea, let $\psi_{X}\left(s_{X} ; X\right)$ be the DM's signal filtering rule for $s_{X}$ when $x$ is chosen from $X$. Then, $\psi_{X}\left(s_{X} ; X\right)=\varnothing$ if the DM receives no news or suppresses $s_{X} \neq \varnothing ; \psi_{X}\left(s_{X} ; X\right)=s_{X}$ if the DM does not suppress $s_{X} \neq \varnothing$. When the DM suppresses a signal, she stops thinking about the reevaluation of the project and chooses the effort level as if she learned nothing. Formally, assume that when the DM chooses her effort, her belief about $\theta_{x}$ is $p\left(\theta_{x} \mid \psi_{x}\left(s_{x} ; X\right)\right)$ given her filtering rule $\psi_{x}$.

Before moving to the analysis of the model, there are some comments on the modeling approach. First, the current paper employs a signal-dependent utility instead of a belief-dependent utility. This is because belief-dependent models with a simple monotonic preference over beliefs or belief changes do not fully capture the subtlety of post-decision dissonance; the DM's utility from a belief induced by dissonant information should not be the same as that from the same belief induced by consonant information. One can still accommodate such subtlety with a belief-dependent utility that is the reduced form of the current model, but the current paper adopts the signal-dependent model since the explicit description of dissonant signals helps us to understand the mechanics of post-decision dissonance.

Second, the current model assumes that the DM has the complete control over her information suppression without any cognitive cost. While the assumption could appear restrictive, the main result of this paper is not driven by this assumption; even if the DM could fail to suppress a signal with some probability and there is also the cognitive cost of suppression, those frictions only diminish the dissonance effect while preserving the main results qualitatively.

Third, as in Compte and Postlewaite (2004) and Brunnermeier and Parker (2005), the DM in this paper takes her controlled perception as given when she chooses the effort level. Alternatively, one could also adopt the intra-personal signaling approach in which the skeptical temporal-self infers the true signal given her past self's memory strategy as in Bénabou and Tirole (2002). If the current problem is analyzed by the alternative approach, the effect of choice set-dependence would be reduced since the DM has less control over her belief. However, since the DM still tries to reduce her dissonance in the alternative approach, the main insight obtained under the alternative assumption remains the same as that under the current assumption. ${ }^{8}$

Finally, in the basic setting, we consider the simple case in which the DM can control her perception only by suppression. In Section 6, we consider the DM who can distort her perception in addition to suppression. It is shown that the main result of this paper is preserved under mild assumptions on the dissonance function.

\subsection{Optimal decision making under dissonance}

It is known that people do not always ignore dissonant information when it is useful or important. ${ }^{9}$ Thus, $^{\text {suppose }}$ that the DM optimally selects whether to suppress dissonant information. Consequently, when the DM chooses whether to suppress a dissonant signal, she faces the following trade-off: if she suppresses information, she can avoid dissonance, while it could lead a suboptimal effort choice. The optimal information filtering rule is then determined by balancing the two effects.

In order to solve the optimal decision problem under dissonance, first, consider her optimal effort choice problem. Suppose the DM chooses a project $x$ and receives $s_{X}$. Let $\tilde{s}_{X}$ be filtered information, that is, $\tilde{s}_{X}=s_{X}$ if she does not suppress the signal; $\tilde{s}_{X}=\varnothing$ if she suppresses $s_{X} \neq \varnothing$ or $s_{X}=\varnothing$. Given $\tilde{s}_{X}$, the DM solves

$$
\max _{e \in E}\left\{\sum_{\theta_{x}} f\left(e, \theta_{x}\right) p\left(\theta_{x} \mid \tilde{s}_{x}\right)-c(e)\right\} \text {. }
$$

Let $e_{x}^{*}\left(\tilde{s}_{x}\right)$ be the optimal effort choice rule.

Given her optimal effort choice rule $e_{x}^{*}\left(\tilde{s}_{x}\right)$, the DM chooses whether to suppress a signal $s_{x}$. If the DM chooses $\tilde{s}_{x}$ given $s_{X}$, the dissonance-adjusted expected utility from project $x$ is

$$
V\left(x \mid s_{x}, \tilde{s}_{x} ; X\right)=\sum_{\theta_{x}} f\left(e_{x}^{*}\left(\tilde{s}_{x}\right), \theta_{x}\right) p\left(\theta_{x} \mid s_{x}\right)-c\left(e_{x}^{*}\left(\tilde{s}_{x}\right)\right)-\gamma_{x}\left(\tilde{s}_{x} ; X\right) .
$$

Then, given $s_{x}$, the DM's optimal suppression decision solves

$$
\max _{\tilde{s}_{x} \in\left\{s_{x}, \varnothing\right\}} V\left(x \mid s_{x}, \tilde{s}_{x} ; X\right) \text {. }
$$

\footnotetext{
${ }^{6}$ In Section 6, it is shown that the main result is preserved under mild assumptions even if we consider a more general information processing rule than the basic setting.

${ }^{7}$ Hardyck and Kardush (1968) argue that the most accessible way to reduce dissonance is to stop thinking about the dissonant cognition, which is empirically supported by Elkin and Leippe (1986). Moreover, Zanna and Aziza (1976) report that distraction that made subjects stop thinking about a dissonant cognition eliminated dissonance. Their findings suggest that the DM in the current paper could eliminate dissonance by stopping the reevaluation of the project by focusing on, say, her task at hand.

8 The assumption of independent temporal selves in the intra-personal signaling models is more fruitful when the DM has the present biased time preference, which creates the conflict of interest between temporal selves, and the later self has an incentive to be skeptical as in Bénabou and Tirole (2002). Note that, in the current paper, when the DM prefers to suppress a signal at the early stage, she still prefers to suppress the signal at the later stage.

9 For example, see Canon (1964) and Freedman (1965).
} 
Let $\psi_{X}^{*}\left(s_{X} ; X\right)$ be the optimal information filtering rule for $s_{X}$ given $X$. Assume that the DM does not suppress a dissonant signal if $V\left(x \mid s_{X}, s_{X} ; X\right)=V\left(x \mid s_{X}, \varnothing ; X\right)$ so that $\psi_{X}^{*}\left(s_{X} ; X\right)$ is unique.

Given $e_{X}^{*}\left(\tilde{S}_{X}\right)$ and $\psi_{x}^{*}\left(s_{X} ; X\right)$, the DM evaluates project $x$. The dissonance-adjusted expected utility from project $x$ is

$$
V^{*}(x ; X)=\sum_{\theta_{x}} \sum_{s_{X}}\left\{f\left(e_{x}^{*}\left(\psi_{x}^{*}\left(s_{x} ; X\right)\right), \theta_{x}\right)-c\left(e_{x}^{*}\left(\psi_{x}^{*}\left(s_{x} ; X\right)\right)\right)-\gamma_{x}\left(\psi_{x}^{*}\left(s_{x} ; X\right) ; X\right)\right\} p\left(s_{x}, \theta_{x}\right)
$$

Then, the optimal project in $X$ under dissonance is the solution of $\max _{x \in X} V^{*}(x ; X)$.

\section{Analysis of optimal decision under dissonance}

This section presents the detailed analysis of the optimal decision under dissonance. After the analysis of some basic dissonance effects, the main result of this paper, choice set-dependent performance, is provided.

\subsection{Dissonance effects}

Given the optimal information filtering rule $\psi_{X}^{*}\left(s_{X} ; X\right)$, define

$$
S_{X}^{\varnothing}(X)=\left\{s_{X} \in S_{X}: \psi_{X}^{*}\left(s_{X} ; X\right)=\varnothing\right\} .
$$

That is, this is the set of signals that are suppressed by the optimal information filtering rule.

Lemma 1. $S_{X}^{\varnothing}(X) \subset S_{X}^{d}(X)$.

Proof. If $s_{x} \neq \varnothing, p\left(\theta_{x} \mid s_{x}\right)$ and $p\left(\theta_{x}\right)$ are ranked in terms of the first-order stochastic dominance by assumption. Then, since $f\left(e, \theta_{x}\right)$ is increasing in $\theta_{x}$ for any $e>\underline{e}$,

$$
\sum_{\theta_{x}} f\left(e, \theta_{x}\right) p\left(\theta_{x}\right) \neq \sum_{\theta_{x}} f\left(e, \theta_{x}\right) p\left(\theta_{x} \mid s_{x}\right)
$$

Then, $e_{x}^{*}(\varnothing) \neq e_{x}^{*}\left(s_{x}\right)$ and hence

$$
\sum_{\theta_{x}} f\left(e_{x}^{*}(\varnothing), \theta_{x}\right) p\left(\theta_{x} \mid s_{x}\right)-c\left(e_{x}^{*}(\varnothing)\right)<\sum_{\theta_{x}} f\left(e_{x}^{*}\left(s_{x}\right), \theta_{x}\right) p\left(\theta_{x} \mid s_{x}\right)-c\left(e_{x}^{*}\left(s_{x}\right)\right) .
$$

If $s_{X} \in S_{X}^{\varnothing}(X)$, then the DM prefers to suppress the signal, that is,

$$
\sum_{\theta_{x}} f\left(e_{x}^{*}(\varnothing), \theta_{x}\right) p\left(\theta_{x} \mid s_{x}\right)-c\left(e_{x}^{*}(\varnothing)\right)>\sum_{\theta_{x}} f\left(e_{x}^{*}\left(s_{x}\right), \theta_{x}\right) p\left(\theta_{x} \mid s_{x}\right)-c\left(e_{x}^{*}\left(s_{x}\right)\right)-\gamma_{x}\left(s_{x} ; X\right) .
$$

Therefore, $\gamma_{x}\left(s_{X} ; X\right)>0$ and thus $s_{X} \in S_{X}^{d}(X)$.

In the literature of escalation of commitment, self-justification always boosts the DM's investment level. However, whether self-justification encourages or discourages the DM's effort depends on the signal structure in the current model. In addition to consonance-dissonance dichotomy, let us divide dissonant signals into two categories; a dissonant signal $s_{X}$ is regular if the dissonant signal is bad news for the chosen project, i.e., $U(x \mid \varnothing)>U\left(x \mid s_{x}\right)$; a dissonant signal is non-regular if it is not regular, that is, the dissonant signal is good news for the chosen project, while it is even better news for some unchosen project and does not support the chosen project anymore. Thus, whenever $s_{x}$ is non-regular, the signal has to be positively correlated with the expected value of some unchosen project.

The next result states that a regular dissonant signal enhances the optimal effort level, whereas a non-regular dissonant signal reduces the optimal effort level.

Proposition 1. If $s_{X}$ is a regular dissonant signal, then $e_{X}^{*}\left(s_{X}\right) \leq e_{X}^{*}\left(\psi_{X}^{*}\left(s_{X} ; X\right)\right)$. Moreover, if $s_{X}$ is a non-regular dissonant signal, then $e_{X}^{*}\left(s_{X}\right) \geq e_{X}^{*}\left(\psi_{X}^{*}\left(s_{X} ; X\right)\right)$.

Proof. See appendix.

When a dissonant signal is regular, the signal reduces the expected utility from the chosen project, that is, a dissonant signal is negative news compared to having no news. Thus, when such a signal is suppressed, the DM's belief is more optimistic than the belief that objectively reflects the signal. As a result, the DM chooses the effort level that is higher than the unbiased choice. On the contrary, when a dissonant signal is not regular, the signal is good news for the chosen project compared to having no news. Thus, when the signal is neglected, the DM chooses the effort level that is lower than that reflects the signal.

Note that Proposition 1 does not claim that a dissonant signal always affects the effort level. A dissonant signal affects the effort level only when the DM chooses to suppress the signal. Hence, if a non-regular dissonant signal, which seems not as intuitive as regular dissonance, has a low $\gamma_{x}\left(s_{X} ; X\right)$, the DM might often choose to face the signal, and her effort choice could rarely be affected.

Proposition 2. For all $x \in X, V^{*}(x ; X) \leq U(x)$. Moreover, if $S_{x}^{d}(X) \neq \emptyset, V^{*}(x ; X)<U(x)$. 
Proof. See appendix.

Proposition 2 suggests that the DM exhibits dissonance aversion; anticipated dissonance discounts the expected utility from a project. The dissonance aversion in the current paper is reminiscent of regret aversion in anticipated regret models such as Bell (1982) and Loomes and Sugden (1982). One major difference is that, unlike the exogenous nature of regret aversion, the degree of dissonance aversion is endogenously determined by the DM's optimal signal filtering rule. The following example shows that the anticipated dissonance could distort the DM's project choice.

Example 4. Suppose $X=\left\{x^{\prime}, x^{\prime \prime}\right\}, f(e, \theta)=\theta e$, and $c(e)=\frac{e^{2}}{2}$. The information structure is such that $\Theta=\{0,1\}, S_{X^{\prime}}=$ $\{0,1, \varnothing\}$ and $S_{x^{\prime \prime}}=\{\varnothing\}$. Assume that $s_{X}$ is independent of $\theta_{x^{\prime}}$ for all $x^{\prime} \neq x$, and that $\operatorname{Pr}\left(s_{X^{\prime}}=1 \mid \theta_{x^{\prime}}=1\right)=0.72, \operatorname{Pr}\left(s_{x^{\prime}}=1 \mid \theta_{x^{\prime}}=\right.$ $0)=0.18, \operatorname{Pr}\left(s_{X^{\prime}}=\varnothing \mid \theta_{x^{\prime}}\right)=0.1$ for all $\theta_{x^{\prime}}, \operatorname{Pr}\left(\theta_{x^{\prime}}=1\right)=0.5$, and $\operatorname{Pr}\left(\theta_{x^{\prime \prime}}=1\right)=0.55$. Finally, suppose $\gamma_{x}\left(s_{x} ; X\right)=0.1$ for any dissonant signal. In this setting, $U\left(x^{\prime}\right)=0.166>U\left(x^{\prime \prime}\right)=0.151$. However, when the DM could experience dissonance, she chooses $x^{\prime \prime}$ since $V^{*}\left(x^{\prime} ; X\right)=0.145<V^{*}\left(x^{\prime \prime} ; X\right)=0.151$.

In the anticipated regret model of Sarver (2008), regret does not distort the DM's project choice. Suppose that the dissonance function is the linear regret function in Sarver (2008), i.e.,

$$
\gamma_{x}\left(s_{x} ; X\right)=\alpha\left[\max _{x^{\prime} \in X} U\left(x^{\prime} \mid s_{X}\right)-U\left(x \mid s_{X}\right)\right]
$$

In this setting, if we assume that the DM cannot control her perception, i.e., $\psi_{X}\left(s_{X}, X\right)=s_{X}$ for all $s_{X}$, the DM in the current paper selects a project as if she maximizes $U(x)$, and her project choice is undistorted as in Sarver (2008). However, since the DM could suppress some signal in the current model, dissonance aversion could still distort the DM's choice under the linear regret setting.

The next result states that when the DM experiences stronger dissonance, the effect of dissonance on the DM's effort level can be magnified.

Proposition 3. Suppose $\gamma_{x}\left(s_{x} ; X\right)<\tilde{\gamma}_{x}\left(s_{x} ; X\right)$ for all $s_{X} \in S_{x}^{d}(X)$. If $s_{X}$ is a regular dissonant signal, then $e_{x}^{*}\left(\psi_{x}\left(s_{x} ; X, \tilde{\gamma}_{x}\right)\right) \geq$ $e_{x}^{*}\left(\psi_{X}\left(s_{X} ; X, \gamma_{x}\right)\right)$. If $s_{X}$ is a non-regular dissonant signal, then $e_{X}^{*}\left(\psi_{X}\left(s_{X} ; X, \tilde{\gamma}_{X}\right)\right) \leq e_{X}^{*}\left(\psi_{X}\left(s_{X} ; X, \gamma_{x}\right)\right)$.

Proof. See appendix.

\subsection{Choice set-dependent performance}

This subsection provides the analysis of choice set-dependent performance.

Lemma 2. For any $X^{\prime \prime} \subset X^{\prime}$, if $x^{\prime} \in X^{\prime \prime}$, then $S_{x^{\prime}}^{\varnothing}\left(X^{\prime \prime}\right) \subset S_{x^{\prime}}^{\varnothing}\left(X^{\prime}\right)$.

Proof. See appendix.

The lemma states that adding options to a choice set enlarges the set of optimally suppressed signals. Note that whenever a signal is dissonant under some choice set, it is also dissonant under an extended choice set, that is, adding options only expands the set of dissonant signals. Then, since the cost of signal-suppression is determined by the distortion generated by the uninformed decision, the cost of suppression is independent of a choice set. Hence, whenever the DM optimally suppresses a dissonant signal under some choice set, it is also optimal for her to suppress the same signal under an extended choice set.

Now, we are ready to provide the central result of this paper. Let

$$
y_{x \mid X^{\prime}}^{*}=\sum_{\theta_{x}} \sum_{s_{x}} f\left(e_{x}^{*}\left(\psi_{x}^{*}\left(s_{x} ; X^{\prime}\right), \theta_{x}\right)\right) p\left(s_{x}, \theta_{x}\right)
$$

That is, this is the expected output of a project $x$ when $x$ is chosen from $X^{\prime}$ and the DM follows the optimal decision rule under dissonance.

Proposition 4. For any $X^{\prime}, X^{\prime \prime}$ such that $X^{\prime \prime} \subset X^{\prime} \subset X$, if $x^{\prime} \in X^{\prime \prime}$, and all signals in $S_{x^{\prime}}^{d}\left(X^{\prime}\right)$ are regular, then $y_{x^{\prime} \mid X^{\prime \prime}}^{*} \leq y_{X^{\prime}}^{*} \mid X^{\prime}$.

Proof. From Lemma 2, $S_{\chi^{\prime}}^{\varnothing}\left(X^{\prime \prime}\right) \subset S_{X^{\prime}}^{\varnothing}\left(X^{\prime}\right) \subset S_{X}$. Thus, we need to consider the following three cases. First, if $s_{X^{\prime}} \in S_{X^{\prime}}^{\varnothing}\left(X^{\prime \prime}\right)$, then $\psi_{X^{\prime}}\left(s_{X^{\prime}} ; X^{\prime \prime}\right)=\psi_{X^{\prime}}\left(s_{X^{\prime}} ; X^{\prime}\right)=\varnothing$. Thus, $e_{X^{\prime}}^{*}\left(\psi_{X^{\prime}}\left(s_{X^{\prime}} ; X^{\prime \prime}\right)\right)=e_{X^{\prime}}^{*}\left(\psi_{X^{\prime}}\left(s_{X^{\prime}} ; X^{\prime}\right)\right)=e_{X^{\prime}}^{*}(\varnothing)$. Second, if $s_{X^{\prime}} \notin S_{X^{\prime}}^{\varnothing}\left(X^{\prime}\right)$, then $\psi_{X^{\prime}}\left(s_{X^{\prime}} ; X^{\prime \prime}\right)=$ $\psi_{X^{\prime}}\left(s_{X^{\prime}} ; X^{\prime}\right)=s_{X^{\prime}}$. Hence, $e_{X^{\prime}}^{*}\left(\psi_{X^{\prime}}\left(s_{X^{\prime}} ; X^{\prime \prime}\right)\right)=e_{X^{\prime}}^{*}\left(\psi_{X^{\prime}}\left(s_{X^{\prime}} ; X^{\prime}\right)\right)=e_{X^{\prime}}^{*}\left(s_{X^{\prime}}\right)$. Finally, if $s_{X^{\prime}} \in S_{X^{\prime}}^{\varnothing}\left(X^{\prime}\right) \backslash S_{X^{\prime}}^{\varnothing}\left(X^{\prime \prime}\right)$, then $\psi_{X^{\prime}}\left(s_{X^{\prime}} ; X^{\prime}\right)=\varnothing$. Since $s_{X^{\prime}}$ is a regular dissonant signal, $e_{X^{\prime}}^{*}\left(s_{X^{\prime}}\right) \leq e_{X^{\prime}}^{*}\left(\psi_{X^{\prime}}\left(s_{X^{\prime}} ; X^{\prime}\right)\right)$ from Proposition 1. Moreover, since $\psi_{X^{\prime}}\left(s_{X^{\prime}} ; X^{\prime \prime}\right)=s_{X^{\prime}}$, $e_{X^{\prime}}^{*}\left(\psi_{X^{\prime}}\left(s_{X^{\prime}} ; X^{\prime \prime}\right)\right)=e_{X^{\prime}}^{*}\left(s_{X^{\prime}}\right)$. Hence, $e_{X^{\prime}}^{*}\left(\psi_{X^{\prime}}\left(s_{X^{\prime}} ; X^{\prime \prime}\right)\right) \leq e_{X^{\prime}}^{*}\left(\psi_{X^{\prime}}\left(s_{X^{\prime}} ; X^{\prime}\right)\right)$. Thus, if all signals in $S_{X^{\prime}}^{d}\left(X^{\prime}\right)$ are regular, $y_{X^{\prime} \mid X^{\prime \prime}}^{*} \leq$ $y_{x^{\prime} \mid X^{\prime}}^{*}$

Note the condition that all dissonant signals are regular is not essential; in fact, Proposition 4 holds as long as a sufficiently large number of dissonant signals are regular.

Proposition 4 provides one possible explanation for the experimental finding in psychology that giving an opportunity of choice can boost people's persistence for the same task, e.g., Zuckerman et al. (1978), Iyengar and Lepper (1999), and 
Cordova and Lepper (1996). Suppose the DM selects one puzzle from a set of puzzles $X$, and let $\theta_{x}$ be the enjoyability of a puzzle $x$. Since the only information about $\theta_{x}$ available after a choice is her experience from a chosen puzzle at the initial stage. A signal $s_{x}$ is interpreted as the DM's experience from her chosen puzzle; for example, she could find a puzzle exciting, tedious, easy, or difficult during the first few minutes. Since her experience tells only about the enjoyability of her current puzzle, whenever it is dissonant, it has to be a negative experience, i.e., regular dissonance. Then, when the puzzle is chosen rather than assigned, she might suppress her negative experience to eliminate her dissonance, and her distorted perception could induce an inflated effort level as Proposition 4 suggests.

Note that from Proposition 1, the DM's effort level could be reduced when she observes a non-regular dissonant signal. Thus, when the effect of non-regular dissonant signals in $S_{x^{\prime}}^{d}\left(X^{\prime}\right)$ dominates the effect of regular dissonant signals, the expected performance can be reduced by a larger choice set. While we can construct such a signal structure, it is not as natural as a signal structure that consists of regular dissonant signals.

Proposition 5. For any $X^{\prime}, X^{\prime \prime}$ such that $X^{\prime \prime} \subset X^{\prime} \subset X$, if $x^{\prime} \in X^{\prime \prime}$, then $V^{*}\left(x^{\prime} ; X^{\prime \prime}\right) \geq V^{*}\left(x^{\prime} ; X^{\prime}\right)$.

Proof. See appendix.

In the standard model, the expected utility from a project is independent of the choice set from which the project is chosen. However, the choice set matters when the DM could experience post-decision dissonance.

Note that Proposition 5 compares two choice sets given a project $x^{\prime}$. Thus, when the DM's choice from $X^{\prime}$ and that from $X^{\prime \prime}$ can be different, whether the DM always prefers a smaller choice set or not is not clear. The following result states that as long as the DM's best choice from $X^{\prime}$ is contained in $X^{\prime \prime}$, the DM prefers a smaller choice set.

Corollary 1. For any $X^{\prime}, X^{\prime \prime}$ such that $X^{\prime \prime} \subset X^{\prime} \subset X$, if $\arg \max _{x \in X^{\prime}} V^{*}\left(x ; X^{\prime}\right) \subset X^{\prime \prime}$, then $\max _{x \in X^{\prime \prime}} V^{*}\left(x ; X^{\prime \prime}\right) \geq \max _{x \in X^{\prime}} V^{*}\left(x ; X^{\prime}\right)$.

Proof. Consider any $x^{\prime} \in \arg \max _{x \in X^{\prime}} V^{*}\left(x ; X^{\prime}\right)$ and $x^{\prime \prime} \in \arg \max _{x \in X^{\prime \prime}} V^{*}\left(x ; X^{\prime \prime}\right)$. If $x^{\prime} \in X^{\prime \prime}$, then by the definition of $x^{\prime \prime}, V^{*}\left(x^{\prime \prime}\right.$; $\left.X^{\prime \prime}\right) \geq V^{*}\left(x^{\prime} ; X^{\prime \prime}\right)$. From Proposition $5, V^{*}\left(x^{\prime} ; X^{\prime \prime}\right) \geq V^{*}\left(x^{\prime} ; X^{\prime}\right)$. Hence, $V^{*}\left(x^{\prime \prime} ; X^{\prime \prime}\right) \geq V^{*}\left(x^{\prime} ; X^{\prime}\right)$.

The idea that the DM could prefer a smaller choice set can also be found in other literature. For example, the DM prefers a smaller choice set to reduce her anticipated regret in Sarver (2008); the DM in Gul and Pesendorfer (2001) prefers a smaller choice that does not contain a tempting option to avoid her self-control cost.

So far, I consider how a larger choice set affects the output and the utility of the DM. The next question is how the attractiveness of an unchosen project could affect the output and the utility of the DM. Since the effect of dissonance is complex, there is no clear-cut result in the general setting. Thus, the current paper focuses on a special class of signal structures to investigate this question. A signal $s_{X}$ is project-specific if $s_{X}$ is independent of $\theta_{x^{\prime}}$ for all $x^{\prime} \neq x$, i.e., $U\left(x^{\prime} \mid s_{X}\right)=$ $U\left(x^{\prime}\right)$ for all $s_{x}$.

The next lemma states that if all signals are project-specific, having an attractive unchosen alternative in a choice set instead of an unattractive unchosen alternative enlarges the set of optimally suppressed signals.

Lemma 3. If $U\left(x^{\prime}\right)>U\left(x^{\prime \prime}\right)>U\left(x^{\prime \prime \prime}\right)$ and all signals in $S_{x^{\prime}}$ are project-specific, then $S_{x^{\prime}}^{\varnothing}\left(\left\{x^{\prime}, x^{\prime \prime \prime}\right\}\right) \subset S_{x^{\prime}}^{\varnothing}\left(\left\{x^{\prime}, x^{\prime \prime}\right\}\right)$.

Proof. See appendix.

If the value of an unchosen alternative could affect the set of optimally suppressed signals, it should also affect the output of the chosen project through the induced effort choice. The following proposition states that when all signals are project-specific and all dissonant signals are regular, the expected output of a project chosen from a set with an attractive alternative is higher than that of the same project chosen from a set with a less attractive alternative.

Proposition 6. Suppose $U\left(x^{\prime}\right)>U\left(x^{\prime \prime}\right)>U\left(x^{\prime \prime \prime}\right)$. If all signals in $S_{x^{\prime}}$ are project-specific and all signals in $S_{x^{\prime}}^{d}\left(\left\{x^{\prime}, x^{\prime \prime}\right\}\right)$ are regular, then $y_{x^{\prime} \mid\left\{x^{\prime}, x^{\prime \prime \prime}\right\}}^{*} \leq y_{x^{\prime} \mid\left\{x^{\prime}, x^{\prime \prime}\right\}}^{*}$

Proof. From Lemma 3, $S_{x^{\prime}}^{\varnothing}\left(\left\{x^{\prime}, x^{\prime \prime \prime}\right\}\right) \subset S_{x^{\prime}}^{\varnothing}\left(\left\{x^{\prime}, x^{\prime \prime}\right\}\right)$ if all signals in $S_{x^{\prime}}$ are project-specific. Thus, we need to check the following three cases. First, if $s_{x^{\prime}} \in S_{x^{\prime}}^{\varnothing}\left(\left\{x^{\prime}, x^{\prime \prime \prime}\right\}\right)$, then $e_{x^{\prime}}^{*}\left(\psi_{x^{\prime}}\left(s_{x^{\prime}} ;\left\{x^{\prime}, x^{\prime \prime}\right\}\right)\right)=e_{x^{\prime}}^{*}\left(\psi_{x^{\prime}}\left(s_{x^{\prime}} ;\left\{x^{\prime}, x^{\prime \prime \prime}\right\}\right)\right)=e_{\chi^{\prime}}^{*}(\varnothing)$. Second, if $s_{x^{\prime}} \notin S_{x^{\prime}}^{\varnothing}\left(\left\{x^{\prime}, x^{\prime \prime}\right\}\right)$, we have $e_{x^{\prime}}^{*}\left(\psi_{x^{\prime}}\left(s_{x^{\prime}} ;\left\{x^{\prime}, x^{\prime \prime}\right\}\right)\right)=e_{x^{\prime}}^{*}\left(\psi_{x^{\prime}}\left(s_{x^{\prime}} ;\left\{x^{\prime}, x^{\prime \prime \prime}\right\}\right)\right)=e_{x^{\prime}}^{*}\left(s_{x^{\prime}}\right)$. Finally, if $s_{x^{\prime}} \in S_{x^{\prime}}^{\varnothing}\left(\left\{x^{\prime}, x^{\prime \prime}\right\}\right) \backslash S_{x^{\prime}}^{\varnothing}\left(\left\{x^{\prime}, x^{\prime \prime \prime}\right\}\right)$, then $e_{x^{\prime}}^{*}\left(\psi_{x^{\prime}}\left(s_{x^{\prime}} ;\left\{x^{\prime}, x^{\prime \prime \prime}\right\}\right)\right)=e_{x^{\prime}}^{*}\left(s_{x^{\prime}}\right)$ and $e_{x^{\prime}}^{*}\left(\psi_{x^{\prime}}\left(s_{x^{\prime}} ;\left\{x^{\prime}, x^{\prime \prime}\right\}\right)\right)=e_{x^{\prime}}^{*}(\varnothing)$. If $s_{x^{\prime}}$ is regular dissonance, $e_{x^{\prime}}^{*}\left(\psi_{x^{\prime}}\left(s_{x^{\prime}} ;\left\{x^{\prime}, x^{\prime \prime \prime}\right\}\right)\right)<$ $e_{x^{\prime}}^{*}\left(\psi_{x^{\prime}}\left(S_{x^{\prime}} ;\left\{x^{\prime}, x^{\prime \prime}\right\}\right)\right)$ from Proposition 1. Thus, if all signals in $S_{x^{\prime}}^{d}\left(\left\{x^{\prime}, x^{\prime \prime}\right\}\right)$ are regular, $y_{x^{\prime}}^{*}\left|\left\{x^{\prime}, x^{\prime \prime \prime}\right\} \leq y_{x^{\prime}}^{*}\right|\left\{x^{\prime}, x^{\prime \prime}\right\}$.

Proposition 6 suggests that the effect of having a more attractive unchosen alternative on the effort level is similar to that of having a larger choice set if all signals are project-specific, and dissonant signals are regular.

Proposition 7. Suppose $U\left(x^{\prime}\right)>U\left(x^{\prime \prime}\right)>U\left(x^{\prime \prime \prime}\right)$. If all signals in $S_{x^{\prime}}$ are project-specific,

$$
V^{*}\left(x^{\prime} ;\left\{x^{\prime}, x^{\prime \prime}\right\}\right) \leq V^{*}\left(x^{\prime} ;\left\{x^{\prime}, x^{\prime \prime \prime}\right\}\right) .
$$

Proof. See appendix. 


\section{Optimal choice set provision}

If unchosen alternatives in a choice set could affect the DM's performance and utility, a manager or a school teacher might utilize the choice set-dependence effect to manage the performance of workers or students. Formally, given a set of feasible projects $X$ and a designer's objective function, the optimal choice set provision problem is to select a subset set $Z \subset X$ that maximizes the objective function when the DM optimally chooses a project from $Z$ and her effort level under dissonance.

There are two natural candidates for a designer's objective function. First, in some cases, the designer might wish to maximize the DM's well-being. Let $x(Z) \in \arg \max _{x} V^{*}(x ; Z)$. Then, a choice set $Z$ is utility-maximizing if it solves

$$
\max _{Z \in P(X)} V^{*}(x(Z) ; Z)
$$

Second, in other situations, a designer might wish to maximize the DM's expected output level. A choice set $Z$ is outputmaximizing if it solves

$$
\max _{Z \in P(X)} y_{x(Z) \mid Z}^{*}
$$

The following proposition states that one can always easily find a utility-maximizing choice set.

Proposition 8. If $x^{\prime} \in \arg \max _{x \in X} U(x)$, then $\left\{x^{\prime}\right\}$ is always an utility-maximizing choice set.

Proof. Suppose that $\left\{x^{\prime}\right\}$ is not a utility-maximizing choice set. Then, there exists $Z^{\prime} \neq\left\{x^{\prime}\right\}$ such that $V^{*}\left(x\left(Z^{\prime}\right) ; Z^{\prime}\right)>V^{*}\left(x^{\prime} ;\left\{x^{\prime}\right\}\right)$. Note that since $V^{*}\left(x\left(Z^{\prime}\right) ;\left\{x\left(Z^{\prime}\right)\right\}\right)=U\left(x\left(Z^{\prime}\right)\right), U\left(x\left(Z^{\prime}\right)\right) \geq V^{*}\left(x\left(Z^{\prime}\right) ; Z^{\prime}\right)$ from Proposition 2. By definition, $U\left(x^{\prime}\right) \geq U\left(x\left(Z^{\prime}\right)\right)$. Hence, $U\left(x^{\prime}\right) \geq V^{*}\left(x\left(Z^{\prime}\right) ; Z^{\prime}\right)$ and thus $V^{*}\left(x^{\prime} ;\left\{x^{\prime}\right\}\right) \geq V^{*}\left(x\left(Z^{\prime}\right) ; Z^{\prime}\right)$, a contradiction.

In short, adding an ex-ante inferior project creates the possibility of experiencing dissonance and inducing a suboptimal effort level. Thus, providing no choice but the best project always maximizes the DM's utility.

One might speculate from Proposition 4 that when all dissonant signals are regular, providing $X$, i.e., all feasible projects, is always an output-maximizing choice set. However, the following example indicates that the design of an outputmaximizing choice set can be delicate.

Example 5. Suppose $X=\left\{x^{\prime}, x^{\prime \prime}, x^{\prime \prime \prime}\right\}, f(e, \theta)=\theta e$, and $c(e)=\frac{e^{2}}{2}$. Moreover, let $\Theta=\{0,1\}$ and assume that $S_{x^{\prime}}=S_{x^{\prime \prime \prime}}=\{\varnothing\}$ and $S_{x^{\prime \prime}}=\{\varnothing, 0,1\}$. Suppose all signals are project-specific, and assume that $\operatorname{Pr}\left(s_{x^{\prime \prime}}=1 \mid \theta_{x^{\prime \prime}}=1\right)=0.72 ; \operatorname{Pr}\left(s_{x^{\prime \prime}}=1 \mid \theta_{x^{\prime \prime}}=\right.$ $0)=0.18 ; \operatorname{Pr}\left(s_{X^{\prime \prime}}=\varnothing \mid \theta_{x^{\prime \prime}}\right)=0.1$ for all $\theta_{x^{\prime \prime}} ; \operatorname{Pr}\left(\theta_{x^{\prime}}=1\right)=0.7 ; \operatorname{Pr}\left(\theta_{X^{\prime \prime}}=1\right)=0.6 ; \operatorname{Pr}\left(\theta_{x^{\prime \prime \prime}}=1\right)=0.4$. Finally, for any $Z \subset X$, $\gamma_{x}\left(s_{x} ; Z\right)=0.1$ for all $s_{x} \in S_{x}^{d}(Z)$.

In this setting, one can find that $U\left(x^{\prime}\right)=0.245, U\left(x^{\prime \prime}\right)=0.218, U\left(x^{\prime \prime \prime}\right)=0.08$, and $V^{*}\left(x^{\prime \prime} ;\left\{x^{\prime \prime}, x^{\prime \prime \prime}\right\}\right)=V^{*}\left(x^{\prime \prime} ; X\right)=0.197$. Moreover, since $x^{\prime}$ and $x / \prime \prime$ are dissonance-free, $U\left(x^{\prime}\right)=V^{*}\left(x^{\prime} ; X\right)$ and $U\left(x^{\prime \prime \prime}\right)=V^{*}\left(x^{\prime \prime \prime} ; X\right)=V^{*}\left(x^{\prime \prime \prime} ;\left\{x^{\prime \prime}, x^{\prime \prime \prime}\right\}\right)$. Thus, $V^{*}\left(x^{\prime}\right.$; $X)>V^{*}\left(x^{\prime \prime} ; X\right)>V^{*}\left(x^{\prime \prime \prime} ; X\right)$ and $V^{*}\left(x^{\prime \prime} ;\left\{x^{\prime \prime}, x^{\prime \prime \prime}\right\}\right)>V^{*}\left(x^{\prime \prime \prime} ;\left\{x^{\prime \prime}, x^{\prime \prime \prime}\right\}\right)$. Hence, if $Z=X$, the DM chooses $x^{\prime}$, whereas she chooses $x^{\prime \prime}$ if $Z=\left\{x^{\prime \prime}, x^{\prime \prime \prime}\right\}$. Then, since the expected outputs from those choices are $y_{x^{\prime \prime} \mid\left\{x^{\prime \prime}, x^{\prime \prime \prime}\right\}}^{*}=0.73$ and $y_{x^{\prime} \mid X}^{*}=0.7$, the outputmaximizing choice set is $\left\{x^{\prime \prime}, x^{\prime \prime \prime}\right\}$ rather than $X$.

In Example 5, while $x^{\prime \prime}$ can be the best performing project with the help of dissonance, the DM never chooses $x^{\prime \prime}$ from $X$ since the dissonance-free choice $x^{\prime}$ is more attractive than $x^{\prime \prime}$. Thus, to make the DM select $x^{\prime \prime}$, we need to make sure that $x^{\prime}$ is not in the choice set. In contrast, adding $x / \prime \prime$ to the choice set is essential; the presence of $x^{\prime \prime \prime}$ triggers dissonance from $x^{\prime \prime}$, whereas $x^{\prime \prime \prime}$ is not attractive enough to distort her choice.

Example 5 suggests that finding an output maximizing choice set is a non-trivial problem in general. The next proposition provides a condition under which the set of all feasible choices $X$ is guaranteed to be an output-maximizing choice set.

Proposition 9. Let $x^{\prime} \in X$ be a project that solves $\max _{x \in X} y_{x \mid X}^{*}$. Suppose that, for any $x \in X$, all signals in $S_{x}^{d}(X)$ are regular. If

$$
U\left(x^{\prime}\right)-\max _{x \in X \backslash\left\{x^{\prime}\right\}} U(x)>\sum_{s_{x^{\prime}}} \gamma_{x^{\prime}}\left(s_{X^{\prime}} ; X\right) p\left(s_{x^{\prime}}\right),
$$

then $X$ is an output-maximizing choice set.

Proof. See appendix.

The condition in Proposition 9 provides the sufficient gap between the expected utility from $x^{\prime}$ and that from the second best project that preserves the desirability of the output maximizing project under the presence of dissonance. To see how the above condition can typically be violated, note that the output-maximizing project often utilizes the dissonance effect to enhance the output level. Thus, the right-hand side of the above inequality could be large, and the condition cannot be satisfied unless the expected utility from $x^{\prime}$ is sufficiently higher than that from the second best choice.

Corollary 2. Let $x^{\prime} \in X$ be a project that solves $\max _{x \in X} y_{x \mid X}^{*}$. Suppose, for any $Z \subset X, \gamma_{x}\left(s_{x} ; Z\right)=k>0$ for all $s_{x} \in S_{x}^{d}(Z)$. Then, the output maximizing choice set is $X$ if 


$$
U\left(x^{\prime}\right)-\max _{x \in X \backslash\left\{x^{\prime}\right\}} U(x)>k \sum_{s_{x^{\prime}} \in S_{x^{\prime}}^{d}(X)} p\left(s_{x^{\prime}}\right) .
$$

The next result states that when the dissonance function is linear in her interim regret, the sufficient gap is proportional to the information value of $s_{x}$.

Corollary 3. Let $x^{\prime} \in X$ be a project that solves $\max _{x \in X} y_{x \mid X}^{*}$. Suppose, for any $Z \subset X$,

$$
\gamma_{x}\left(s_{x} ; Z\right)=\alpha\left[\max _{z \in Z} U\left(z \mid s_{x}\right)-U\left(x \mid s_{x}\right)\right] .
$$

Then, the output maximizing choice set is $X$ if

$$
U\left(x^{\prime}\right)-\max _{x \in X \backslash\left\{x^{\prime}\right\}} U(x)>\alpha\left[\sum_{s_{x^{\prime}} \in S_{x^{\prime}}} U\left(z\left(s_{x^{\prime}}\right) \mid s_{x^{\prime}}\right) p\left(s_{x^{\prime}}\right)-U\left(x^{\prime}\right)\right]
$$

where

$$
z\left(s_{x^{\prime}}\right) \in \arg \max _{z \in X} U\left(z \mid s_{x^{\prime}}\right) .
$$

Corollary 3 suggests that when the dissonance term is increasing in the degree of interim regret, and the value of the best project heavily depends on "option value," the design of the output maximizing choice set becomes a delicate problem.

\section{Discussion}

\subsection{Generalization}

In order to focus on the main idea, the basic model considers a simple form of dissonance management; the DM decides whether to suppress a dissonant signal. In a more general setting, the DM might discount the negative implication of a dissonance signal without suppressing it. For example, suppose a DM chooses her project whose ex ante expected profit is 10. When some negative event occurs and some expert claims that it reduces the expected profit of her project to 8 , she could somehow manage to believe that the expert is wrong, and the expected profit is still 9 .

Since a signal filtering rule $\psi_{x}\left(s_{x} ; X\right)$ can only suppress information, we need to consider a general information processing rule to accommodate distorted perception. Formally, an information processing rule is $\phi_{x}\left(s_{x} ; X\right) \in S_{x}$, which generates the DM's perception of a signal $s_{X}$ when a project $x$ is chosen from a choice set $X$. Assume that when the DM selects $x$ from $X$ and processes $s_{X}$ with $\phi_{x}$, her dissonance level is $\gamma_{x}\left(\phi_{x}\left(s_{x} ; X\right) ; X\right)$, and her belief about $\theta_{x}$ is $p\left(\theta_{x} \mid \phi_{x}\left(s_{x} ; X\right)\right.$ ).

Let $\tilde{s}_{x}$ be the DM's perception of $s_{x}$, and let $e_{x}^{*}\left(\tilde{s}_{x}\right)$ be the DM's optimal effort choice rule as in the basic model. Then, if the DM chooses $\tilde{s}_{x}$ given $s_{X}$, the dissonance-adjusted expected utility from project $x$ is

$$
V\left(x \mid s_{x}, \tilde{s}_{x} ; X\right)=\sum_{\theta_{x}} f\left(e_{x}^{*}\left(\tilde{s}_{x}\right), \theta_{x}\right) p\left(\theta_{x} \mid s_{X}\right)-c\left(e_{x}^{*}\left(\tilde{s}_{x}\right)\right)-\gamma_{x}\left(\tilde{s}_{x} ; X\right) .
$$

An information processing rule is optimal if, given $s_{x}$, her perception $\tilde{s}_{x}$ solves

$$
\max _{\tilde{s}_{x} \in S_{x}} V\left(x \mid s_{X}, \tilde{s}_{x} ; X\right) .
$$

To obtain a clear-cut result under a general information processing rule, we need an additional assumption on the dissonance function. Recall that signals in $S_{x}$ are ranked in terms of stochastic dominance. Then, assign a number to each signal so that a larger number means a more positive signal. A dissonance function $\gamma_{X}$ has weakly increasing difference property if, whenever $X \subset X^{\prime}$,

$$
\gamma_{x}\left(s_{x} ; X\right)-\gamma_{x}\left(s_{x}^{\prime} ; X\right) \leq \gamma_{x}\left(s_{x} ; X^{\prime}\right)-\gamma_{x}\left(s_{x}^{\prime} ; X^{\prime}\right)
$$

for any $s_{x}, s_{x}^{\prime} \in S_{x}^{d}(X) \cap S_{x}^{d}\left(X^{\prime}\right)$ such that $s_{X} \leq s_{x}^{\prime}$. That is, the difference between the dissonance from one dissonant signal and that from a more positive dissonant signal should not be reduced when the underlying choice set expands. Many dissonance functions possess this property; for example, the assumption is satisfied under the constant dissonance function, i.e., $\gamma_{x}\left(s_{x} ; X\right)=k$ for all $s_{X} \in S_{x}^{d}(X)$; the dissonance function with linear regret, i.e., $\gamma_{X}\left(s_{x} ; X\right)=\alpha\left[\max _{z \in X} U\left(z \mid s_{X}\right)-U\left(x \mid s_{X}\right)\right]$, also satisfies the assumption.

Proposition 10. Suppose that, in addition to the assumptions on $\gamma_{x}$ in the basic model, $\gamma_{X}$ is weakly decreasing in $s_{X}$ and has weakly increasing difference property. If $X \subset X^{\prime}$, then, for any $x \in X, y_{x \mid X}^{*} \leq y_{x \mid X^{\prime}}^{*}$ under some optimal information processing rules.

Proof. See appendix.

When the dissonance function has weakly increasing difference property, we can show that there exists an optimal information processing rule that satisfies some simple properties under each choice set. Then, from the basic properties, it can be shown that if the dissonance function is also weakly decreasing in $s_{x}$, a larger choice set weakly enhances the DM's output as in the basic model. 
While Proposition 10 does not directly impose any restriction on the signal structure, the condition on $\gamma_{x}$ indirectly restricts the underlying signal structure. In fact, when the dissonance function is weakly decreasing in $s_{x}$, dissonant signals need to be regular under any dissonance function. ${ }^{10}$

Weakly increasing difference property is a condition that is not required in the basic setting. However, this natural condition is not a necessary condition for the main result. Thus, the performance enhancement effect of a large choice set is a fairly robust phenomenon that is preserved under a general information processing rule.

\subsection{Escalation of commitment}

The role of cognitive dissonance in the current paper might remind some readers of escalation of commitment; after an initial investment for a project, people tend to continue investing in the project even if they observe negative outcomes, especially when they personally feel responsible about their choices. ${ }^{11}$ In fact, one of the major explanations for escalation of commitment is based on cognitive dissonance, e.g., Staw (1976), Eyster (2002), and Yariv (2002). Even though the current model is not built for analyzing escalation of commitment, the current model can also provide some sharp insights into the phenomenon.

Suppose there is a project $x_{1}$, which requires an initial investment $I$. If the DM chooses to invest, she observes a signal $s_{x_{1}}$, which is interpreted as the preliminary performance of the project $x_{1}$ at the first period. She then decides the amount of her subsequent investment $e$ for the project at the second period. Suppose that when the DM initiates the project $x_{1}$, her utility from $(y, e)$ given $s_{x_{1}}$ is

$$
y-e-\gamma_{x_{1}}\left(s_{x_{1}} ;\left\{x_{1}, x_{2}\right\}\right)-I .
$$

Then, modify the definition of $U\left(x_{1} \mid s_{x_{1}}\right)$ such that

$$
\sum_{\theta_{x}} f\left(e_{x_{1}}^{*}\left(s_{x_{1}}\right), \theta_{x_{1}}\right) p\left(\theta_{x_{1}} \mid s_{x_{1}}\right)-e_{x_{1}}^{*}\left(s_{x_{1}}\right)-I
$$

Now consider "not initiate project $x_{1}$ " as the alternative "project" denoted by $x_{2}$, which always gives the DM utility of 0 , i.e., $U\left(x_{2}\right)=0$. Since $U\left(x_{2} \mid s_{x_{1}}\right)=0$ for any signal, a signal $s_{x_{1}}$ is dissonant if

$$
U\left(x_{1} \mid s_{x_{1}}\right)-I<0 \text {. }
$$

Thus, any dissonant signal $s_{x_{1}}$ needs to be regular in this setting. Then, from Proposition 1, the optimal effort level given a dissonant signal is weakly higher than that without dissonance, and the excessive effort level can be interpreted as escalation of commitment.

The current model also provides some implications that are consistent with stylized facts in the literature of escalation of commitment. ${ }^{12}$ First, the DM's sense of responsibility about her investment decision is known to be an essential factor that triggers escalation of commitment. This stylized fact is consistent with the result in the current paper that the DM chooses an excessively high effort level only if the DM has an investment decision to make, i.e., $X=\left\{x_{1}, x_{2}\right\}$. Note that when $X=\left\{x_{1}\right\}$, the DM would not feel any responsibility about a negative signal $s_{x_{1}}$ as it is not a consequence of her initial investment decision. The second stylized fact is that the amount of the initial investment tends to be positively associated with the degree of an excessive investment. This stylized fact is consistent with Proposition 6; the expected excessive effort level is higher when project $x_{1}$ requires a higher level of the initial investment.

\subsection{Can anticipated regret explain the choice provision effect?}

In the current model, the DM's effort level for a project chosen from a set of projects can be higher than that for the same project that is assigned without choice, i.e., choice provision effect. In this subsection, it is shown that standard anticipated regret models such as Loomes and Sugden (1982) and Savage (1954) do not produce such a choice provision effect in the current decision problem.

First, consider the regret model in Loomes and Sugden (1982). Since their model lacks transitivity, the application of their model is most effective when we analyze a binary choice problem. Thus, consider the current decision problem with a binary effort choice setting. Suppose that the DM has selected project $x^{\prime}$ and observed some signal $s_{x^{\prime}}$. To select her effort level, the DM in the anticipated regret model compares her utility from one effort level $e^{\prime}$ and that from another effort level $e$ given her chosen project $x^{\prime}$, which is uncontrollable at this stage. Let $W\left(e, \theta_{x^{\prime}}\right)$ be the DM's ex-post utility from $e$ when $x^{\prime}$ is her chosen project and the productivity of $x^{\prime}$ is $\theta_{x^{\prime}}$. That is,

$$
W\left(e, \theta_{x^{\prime}}\right)=f\left(e, \theta_{x^{\prime}}\right)-c(e) .
$$

\footnotetext{
${ }^{10}$ If a dissonant signal is non-regular, the signal is more positive than $\varnothing$. The dissonance function is then not weakly decreasing.

11 The term escalation of commitment and sunk cost fallacy are used interchangeably by some researchers since both describe a DM's excessive persistence after her initial investment. However, there is a subtle difference between the two phenomena; escalation of commitment emphasizes people's tendency to ignore or discount negative information after the initial investment, whereas sunk cost fallacy usually does not emphasize the DM's distorted perception.

${ }^{12}$ See Sleesman et al. (2012) for the comprehensive meta-analysis of the existing experimental findings in the literature of escalation of commitment.
} 
Based on Loomes and Sugden (1982), when the regret averse DM compares $e^{\prime}$ with $e$, her modified utility from $e^{\prime}$ is

$$
\sum_{\theta_{x^{\prime}}}\left[W\left(e^{\prime}, \theta_{x^{\prime}}\right)+R\left(W\left(e^{\prime}, \theta_{x^{\prime}}\right)-W\left(e, \theta_{x^{\prime}}\right)\right)\right] p\left(\theta_{x^{\prime}} \mid s_{x^{\prime}}\right)
$$

where $R$ is a regret function. Then, given her project $x^{\prime}$ and a signal $s_{x^{\prime}}$, the regret averse DM prefers $e^{\prime}$ to $e$ if and only if

$$
\begin{aligned}
& \sum_{\theta_{x^{\prime}}}\left[W\left(e^{\prime}, \theta_{x^{\prime}}\right)+R\left(W\left(e^{\prime}, \theta_{x^{\prime}}\right)-W\left(e, \theta_{x^{\prime}}\right)\right)\right] p\left(\theta_{x^{\prime}} \mid s_{x^{\prime}}\right) \\
& \geq \quad \sum_{\theta_{x^{\prime}}}\left[W\left(e, \theta_{x^{\prime}}\right)+R\left(W\left(e, \theta_{x^{\prime}}\right)-W\left(e^{\prime}, \theta_{x^{\prime}}\right)\right)\right] p\left(\theta_{x^{\prime}} \mid s_{x^{\prime}}\right)
\end{aligned}
$$

Note that, given a chosen project $x^{\prime}$ and a signal $s_{x^{\prime}}$, the regret averse DM's preference over effort levels is independent of an unchosen project. That is, the regret averse DM's effort choice for a project $x^{\prime}$ does not depend on whether $x^{\prime}$ is chosen or assigned. Thus, their anticipated regret theory could distort the DM's effort choice, but it does not exhibit any dependence on an unchosen project.

Another type of anticipated regret theory is min-max regret proposed by Savage (1954). According to this theory, the DM makes her decision to minimize her worst case regret that could be generated by her decision. ${ }^{13}$ To analyze the DM's effort choice, suppose that she has already selected a project $x^{\prime}$. Then, at her effort choice stage, her ex-post regret from $e^{\prime}$ for the project $x^{\prime}$ is given by

$$
L\left(e^{\prime}, \theta_{x^{\prime}}\right)=\max _{e \in E} W\left(e, \theta_{x^{\prime}}\right)-W\left(e^{\prime}, \theta_{x^{\prime}}\right) .
$$

Then, the DM selects her effort level for her project $x^{\prime}$ to minimize her worst case regret, i.e.,

$$
\min _{e^{\prime} \in E} \max _{x_{x^{\prime}} \in \Theta} L\left(e^{\prime}, \theta_{x^{\prime}}\right) \text {. }
$$

Clearly, the DM's effort choice does not depend on whether $x^{\prime}$ is chosen or assigned.

To sum up, in anticipated regret models, the DM deals with her future regret that could be created by her current controllable action. Since a project is already chosen and fixed at the DM's effort choice stage in the current decision problem, her effort choice could be affected by her unchosen effort level but not by her unchosen project in anticipated regret models.

\subsection{Dissonance from effort}

The current paper considers the DM who experiences post-decision dissonance only from her project choice. In principle, we could consider the DM who experiences post-decision dissonance also from her effort choice when she observes the final output $y$ that does not support her effort choice. However, the results of this paper are unaffected even if the dissonance from her effort choice is incorporated into the model.

To see this claim, suppose that the model is extended so that the DM experiences dissonance from her effort choice when $y$ is dissonant information. Note that since there is no future action that can be distorted by suppressing information $y$, there is no cost from suppressing dissonant $y$. Thus, regardless of her effort choice, the DM can always eliminate any dissonance from her effort choice. Knowing that she can eliminate her future dissonance without any cost, the DM can choose her effort level as if there is no future dissonance from her effort choice.

\section{Concluding remarks}

This paper analyzed the optimal decision making of the DM who rationally filters information to manage her postdecision cognitive dissonance. It is shown that when post-decision dissonance is carefully formulated, the DM's optimal effort level exhibits choice set-dependence that can explain the choice provision effect. It is also found that the nature of choice set-dependence is determined by the signal structure, and the degree of choice-set dependence can be affected by the size and the composition of a choice set. This paper also explored the optimal choice set design. The utility-maximizing choice set consists only of the best project, whereas there is no simple solution for the output maximizing choice set in general.

One of the major applications of the current model could be found in models of principal-agent with delegation. The current paper suggests that when the agent could experience post-decision dissonance, the delegation set is a new instrument to deal with moral hazard problems. Moreover, the optimal delegation needs to take into account the choice-compatibility condition; the agent with dissonance could select a dissonance-free project rather than the output-maximizing project even if the standard incentive condition is satisfied.

Finally, while the current paper proposes one plausible explanation for the choice provision effect, there can be other psychological factors that also contribute to the choice provision effect, e.g., Deci and Ryan (1985). ${ }^{14}$ The benefit of the

\footnotetext{
13 The DM with min-max regret ignores the probability of $\theta_{x^{\prime}}$, that is, no signal $s_{x^{\prime}}$ can affect the DM's effort choice. This nature makes the application of min-max regret to the current decision problem questionable.

14 Deci and Ryan (1985) propose self-determination theory to explain the choice provision effect. This psychological theory claims that since people enjoy autonomy, the opportunity of choice enhances their intrinsic motivation.
} 
current approach is in the richness of implications; by endogenizing the choice provision effect, the current paper provides insights into how the underlying setting such as the size/composition of choice set and an information structure could affect the DM's performance.

\section{Appendix A. Appendix}

\section{A1. Proof of Proposition 1}

To prove the first part of Proposition 1 , suppose that $s_{x}$ is regular dissonance, but $e_{x}^{*}(\varnothing)<e_{x}^{*}\left(s_{x}\right)$. Then, since $f_{e}>0$ and $f_{e e} \leq 0$ whereas $c_{e}>0$ and $c_{e e}>0$,

$$
\sum_{\theta_{x}} f_{e}\left(e_{x}^{*}(\varnothing), \theta_{x}\right) p\left(\theta_{x} \mid s_{x}\right)-c_{e}\left(e_{x}^{*}(\varnothing)\right)>0
$$

From the first order condition,

$$
\sum_{\theta_{x}} f_{e}\left(e_{x}^{*}(\varnothing), \theta_{x}\right) p\left(\theta_{x} \mid \varnothing\right)-c_{e}\left(e_{x}^{*}(\varnothing)\right)=0 .
$$

Then,

$$
\sum_{\theta_{x}} f_{e}\left(e_{x}^{*}(\varnothing), \theta_{x}\right) p\left(\theta_{x} \mid s_{x}\right)>\sum_{\theta_{x}} f_{e}\left(e_{x}^{*}(\varnothing), \theta_{x}\right) p\left(\theta_{x} \mid \varnothing\right) .
$$

Note that $\varnothing$ and any $s_{x} \neq \varnothing$ are ranked in terms of the first-order stochastic dominance by assumption. Then, since $f_{e}\left(e_{x}^{*}\left(s_{x}\right), \theta_{x}\right)$ is increasing in $\theta_{x}, p\left(\theta_{x} \mid s_{x}\right)$ must first-order stochastically dominates $p\left(\theta_{x} \mid \varnothing\right)$. Since $f\left(e, \theta_{x}\right)$ is increasing in $\theta_{x}$ given any $e>0$, it follows that

$$
\sum_{\theta_{x}}\left[f\left(e_{x}^{*}(\varnothing), \theta_{x}\right)-c\left(e_{x}^{*}(\varnothing)\right)\right] p\left(\theta_{x} \mid s_{x}\right)>\sum_{\theta_{x}}\left[f\left(e_{x}^{*}(\varnothing), \theta_{x}\right)-c\left(e_{x}^{*}(\varnothing)\right)\right] p\left(\theta_{x} \mid \varnothing\right) .
$$

Since $e_{x}^{*}\left(s_{X}\right)$ is the optimal effort level given $s_{x}$,

$$
\sum_{\theta_{x}}\left[f\left(e_{x}^{*}\left(s_{x}\right), \theta_{x}\right)-c\left(e_{x}^{*}\left(s_{x}\right)\right)\right] p\left(\theta_{x} \mid s_{x}\right)>\sum_{\theta_{x}}\left[f\left(e_{x}^{*}(\varnothing), \theta_{x}\right)-c\left(e_{x}^{*}(\varnothing)\right)\right] p\left(\theta_{x} \mid s_{x}\right) .
$$

Hence,

$$
\sum_{\theta_{x}}\left[f\left(e_{x}^{*}\left(s_{x}\right), \theta_{x}\right)-c\left(e_{x}^{*}\left(s_{x}\right)\right)\right] p\left(\theta_{x} \mid s_{x}\right)>\sum_{\theta_{x}}\left[f\left(e_{x}^{*}(\varnothing), \theta_{x}\right)-c\left(e_{x}^{*}(\varnothing)\right)\right] p\left(\theta_{x} \mid \varnothing\right) .
$$

That is, $U\left(x \mid s_{x}\right)>U(x \mid \varnothing)$. But then $s_{x}$ is not regular dissonance, a contradiction.

The proof of the second part is analogous to the first part. Suppose that $s_{x}$ is non-regular dissonance, but $e_{x}^{*}(\varnothing)>e_{x}^{*}\left(s_{x}\right)$. Then, from the assumptions on $f$ and $c$,

$$
\sum_{\theta_{x}} f_{e}\left(e_{x}^{*}\left(s_{x}\right), \theta_{x}\right) p\left(\theta_{x} \mid \varnothing\right)-c_{e}\left(e_{x}^{*}\left(s_{x}\right)\right)>0 .
$$

From the first order condition,

$$
\sum_{\theta_{x}} f_{e}\left(e_{x}^{*}\left(s_{x}\right), \theta_{x}\right) p\left(\theta_{x} \mid s_{x}\right)-c_{e}\left(e_{x}^{*}\left(s_{x}\right)\right)=0 .
$$

Hence,

$$
\sum_{\theta_{x}} f_{e}\left(e_{x}^{*}\left(s_{x}\right), \theta_{x}\right) p\left(\theta_{x} \mid s_{x}\right)<\sum_{\theta_{x}} f_{e}\left(e_{x}^{*}\left(s_{x}\right), \theta_{x}\right) p\left(\theta_{x} \mid \varnothing\right) .
$$

Since $\varnothing$ and any $s_{x} \neq \varnothing$ are ranked in terms of the stochastic dominance, $p\left(\theta_{x} \mid s_{x}\right)$ must be first-order stochastically dominated by $p\left(\theta_{x} \mid \varnothing\right)$. It follows that

$$
\sum_{\theta_{x}}\left[f\left(e_{x}^{*}\left(s_{x}\right), \theta_{x}\right)-c\left(e_{x}^{*}\left(s_{x}\right)\right)\right] p\left(\theta_{x} \mid s_{x}\right)<\sum_{\theta_{x}}\left[f\left(e_{x}^{*}\left(s_{x}\right), \theta_{x}\right)-c\left(e_{x}^{*}\left(s_{x}\right)\right)\right] p\left(\theta_{x} \mid \varnothing\right) .
$$

Since $e_{x}^{*}(\varnothing)$ is the optimal effort level given $\varnothing$,

$$
\sum_{\theta_{x}}\left[f\left(e_{x}^{*}\left(s_{x}\right), \theta_{x}\right)-c\left(e_{x}^{*}\left(s_{x}\right)\right)\right] p\left(\theta_{x} \mid \varnothing\right)<\sum_{\theta_{x}}\left[f\left(e_{x}^{*}(\varnothing), \theta_{x}\right)-c\left(e_{x}^{*}(\varnothing)\right)\right] p\left(\theta_{x} \mid \varnothing\right) .
$$

Therefore,

$$
\sum_{\theta_{x}}\left[f\left(e_{x}^{*}\left(s_{x}\right), \theta_{x}\right)-c\left(e_{x}^{*}\left(s_{x}\right)\right)\right] p\left(\theta_{x} \mid s_{x}\right)<\sum_{\theta_{x}}\left[f\left(e_{x}^{*}(\varnothing), \theta_{x}\right)-c\left(e_{x}^{*}(\varnothing)\right)\right] p\left(\theta_{x} \mid \varnothing\right) .
$$

But then $s_{x}$ is not non-regular dissonance, a contradiction. 


\section{A2. Proof of Proposition 2}

From Lemma $1, S_{X}^{\varnothing}(X) \subset S_{X}^{d}(X) \subset S_{X}$. Hence, we need to consider the following three cases.

First, if $s_{X} \in S_{X} \backslash S_{X}^{d}(X)$, then $\gamma_{x}\left(s_{X} ; X\right)=0$ and so $\psi_{X}^{*}\left(s_{X} ; X\right)=s_{X}$. Thus, $U\left(x \mid s_{X}\right)=V\left(x \mid s_{X}, \psi_{X}^{*}\left(s_{X} ; X\right), X\right)$.

Second, if $s_{X} \in S_{X}^{d}(X) \backslash S_{X}^{\varnothing}(X)$, then $\psi_{X}^{*}\left(s_{X} ; X\right)=s_{X}$ and

$$
V\left(x \mid s_{x}, \psi_{x}^{*}\left(s_{x} ; X\right), X\right)=\sum_{\theta_{x}} f\left(e_{x}^{*}\left(s_{x}\right), \theta_{x}\right) p\left(\theta_{x} \mid s_{x}\right)-c\left(e_{x}^{*}\left(s_{x}\right)\right)-\gamma_{x}\left(s_{x} ; X\right)
$$

Since $\gamma_{x}\left(s_{X} ; X\right)>0$, we have $U\left(x \mid s_{X}\right)>V\left(x \mid s_{X}, \psi_{X}^{*}\left(s_{x} ; X\right), X\right)$.

Finally, if $s_{x} \in S_{x}^{\varnothing}(X)$, then

$$
V\left(x \mid s_{x}, \psi_{x}^{*}\left(s_{x} ; X\right), X\right)=\sum_{\theta_{x}} f\left(e_{x}^{*}(\varnothing), \theta_{x}\right) p\left(\theta_{x} \mid s_{X}\right)-c\left(e_{x}^{*}(\varnothing)\right) .
$$

Since any $s_{X} \neq \varnothing$ and $\varnothing$ are strictly ranked in terms of first-order stochastic dominance, $e_{x}^{*}(\varnothing)$ is suboptimal given $s_{X}$. That is,

$$
\sum_{\theta_{x}} f\left(e_{x}^{*}(\varnothing), \theta_{x}\right) p\left(\theta_{x} \mid s_{x}\right)-c\left(e_{x}^{*}(\varnothing)\right)<\sum_{\theta_{x}} f\left(e_{x}^{*}\left(s_{x}\right), \theta_{x}\right) p\left(\theta_{x} \mid s_{x}\right)-c\left(e_{x}^{*}\left(s_{x}\right)\right)
$$

Thus, $U\left(x \mid s_{X}\right)>V\left(x \mid s_{X}, \psi_{x}^{*}\left(s_{X} ; X\right), X\right)$.

From the three cases, $U(x) \geq V^{*}(x ; X)$. Moreover, if $S_{X}^{d}(X) \neq \emptyset$, then $U(x)>V^{*}(x ; X)$.

\section{A3. Proof of Proposition 3}

Let $\psi_{x}^{*}\left(s_{x} ; X, \gamma_{x}\right)$ be the optimal information filtering rule for signal $s_{X}$ when the DM with $\gamma_{x}$ selects $x$ from $X$. Moreover, let $S_{x}^{\varnothing}\left(X ; \gamma_{x}\right)$ be $S_{x}^{\varnothing}(X)$ under $\gamma_{x}$.

First, I claim that if $\gamma_{x}\left(s_{X} ; X\right)<\tilde{\gamma}_{X}\left(s_{X} ; X\right)$ for all $s_{X} \in S_{X}^{d}(X)$, then $S_{X}^{\varnothing}\left(X ; \gamma_{X}\right) \subset S_{X}^{\varnothing}\left(X ; \tilde{\gamma}_{x}\right)$. To see the claim, suppose $\psi_{x}^{*}\left(s_{x} ; X, \gamma_{x}\right)=\varnothing$ for $s_{X} \in S_{x}^{d}(X)$. Then,

$$
\sum_{\theta_{x}} f\left(e_{x}^{*}(\varnothing), \theta_{x}\right) p\left(\theta_{x} \mid s_{x}\right)-c\left(e_{x}^{*}(\varnothing)\right) \geq \sum_{\theta_{x}} f\left(e_{x}^{*}\left(s_{x}\right), \theta_{x}\right) p\left(\theta_{x} \mid s_{x}\right)-c\left(e_{x}^{*}\left(s_{x}\right)\right)-\gamma_{x}\left(s_{x} ; X\right) .
$$

If $\gamma_{X}\left(s_{X} ; X\right)<\tilde{\gamma}_{X}\left(s_{X} ; X\right)$ for all $s_{X} \in S_{X}^{d}(X)$,

$$
\sum_{\theta_{x}} f\left(e_{x}^{*}(\varnothing), \theta_{x}\right) p\left(\theta_{x} \mid s_{X}\right)-c\left(e_{x}^{*}(\varnothing)\right)>\sum_{\theta_{x}} f\left(e_{x}^{*}\left(s_{X}\right), \theta_{x}\right) p\left(\theta_{x} \mid s_{X}\right)-c\left(e_{x}^{*}(s)\right)-\tilde{\gamma}_{x}\left(s_{x} ; X\right) .
$$

Hence, $\psi_{x}^{*}\left(s_{x} ; X, \tilde{\gamma}_{x}\right)=\varnothing$.

Since $S_{X}^{\varnothing}\left(X ; \gamma_{x}\right) \subset S_{X}^{\varnothing}\left(X ; \tilde{\gamma}_{x}\right)$, we need to check the following three cases to prove Proposition 3 .

First, if $s_{X} \in S_{X} \backslash S_{X}^{\varnothing}\left(X ; \tilde{\gamma}_{x}\right)$, then $\psi_{X}^{*}\left(s_{X} ; X, \gamma_{x}\right)=\psi_{X}^{*}\left(s_{x} ; X, \tilde{\gamma}_{x}\right)=s_{X}$ and thus $e_{X}^{*}\left(\psi_{X}^{*}\left(s_{x} ; X, \tilde{\gamma}_{x}\right)\right)=e_{x}^{*}\left(\psi_{X}^{*}\left(s_{x} ; X, \gamma_{x}\right)\right)=e_{x}^{*}\left(s_{X}\right)$.

Second, if $s_{X} \in S_{X}^{\varnothing}\left(X ; \gamma_{x}\right)$, then $\psi_{x}^{*}\left(s_{x} ; X, \gamma_{x}\right)=\psi_{x}^{*}\left(s_{X} ; X, \tilde{\gamma}_{x}\right)=\varnothing$ and thus $e_{X}^{*}\left(\psi_{x}\left(s_{x} ; X, \tilde{\gamma}_{x}\right)\right)=e_{X}^{*}\left(\psi_{x}^{*}\left(s_{X} ; X, \gamma_{x}\right)\right)=e_{x}^{*}(\varnothing)$.

Finally, if $s_{X} \in S_{X}^{\varnothing}\left(X ; \tilde{\gamma}_{x}\right) \backslash S_{X}^{\varnothing}\left(X ; \gamma_{x}\right)$, then $\psi_{x}^{*}\left(s_{x} ; X, \tilde{\gamma}_{x}\right)=\varnothing$ and $\psi_{x}^{*}\left(s_{x} ; X, \gamma_{x}\right)=s_{x}$. From Proposition 1 , if $s_{X}$ is a regular dissonant signal, $e_{x}^{*}\left(\psi_{X}^{*}\left(s_{x} ; X, \tilde{\gamma}_{x}\right)\right) \geq e_{X}^{*}\left(s_{X}\right)$, whereas if $s_{X}$ is not a regular dissonant signal, $e_{X}^{*}\left(\psi_{X}^{*}\left(s_{x} ; X, \tilde{\gamma}_{x}\right)\right) \leq e_{X}^{*}\left(s_{X}\right)$. Then, the result follows from the three cases.

\section{A4. Proof of Lemma 2}

Suppose $s_{X^{\prime}}$ is a dissonant signal under $X^{\prime \prime}$. Then, if the DM does not suppress the signal,

$$
V\left(x^{\prime} \mid s_{x^{\prime}}, s_{x^{\prime}}, X^{\prime \prime}\right)=\sum_{\theta_{x^{\prime}}} f\left(e_{x^{\prime}}^{*}\left(s_{x^{\prime}}\right), \theta_{x^{\prime}}\right) p\left(\theta_{x^{\prime}} \mid s_{x^{\prime}}\right)-c\left(e_{x^{\prime}}^{*}\left(s_{x^{\prime}}\right)\right)-\gamma_{x^{\prime}}\left(s_{x^{\prime}} ; X^{\prime \prime}\right) .
$$

Note that if $\max _{z \in X^{\prime \prime}} U\left(z \mid s_{X}\right)>U\left(x \mid s_{X}\right)$ and $X^{\prime \prime} \subset X^{\prime}$, then $\max _{z \in X^{\prime}} U\left(z \mid s_{X}\right)>U\left(x \mid s_{X}\right)$. Thus, $S_{X}^{d}\left(X^{\prime \prime}\right) \subset S_{x}^{d}\left(X^{\prime}\right)$. Then, $s_{X^{\prime}} \in S_{X^{\prime}}^{d}\left(X^{\prime}\right)$ and so $\gamma_{x^{\prime}}\left(s_{X^{\prime}} ; X^{\prime \prime}\right) \leq \gamma_{x^{\prime}}\left(s_{X^{\prime}} ; X^{\prime}\right)$. Hence,

$$
V\left(x^{\prime} \mid s_{X^{\prime}}, s_{X^{\prime}}, X^{\prime}\right) \leq V\left(x^{\prime} \mid s_{X^{\prime}}, s_{X^{\prime}}, X^{\prime \prime}\right) \text {. }
$$

On the other hand, when $s_{X^{\prime}}$ is suppressed,

$$
V\left(x^{\prime} \mid s_{x^{\prime}}, \varnothing, X^{\prime \prime}\right)=V\left(x^{\prime} \mid s_{x^{\prime}}, \varnothing, X^{\prime}\right)=\sum_{\theta_{x^{\prime}}} f\left(e_{x^{\prime}}^{*}(\varnothing), \theta_{x^{\prime}}\right) p\left(\theta_{x^{\prime}} \mid \varnothing\right)-c\left(e_{x^{\prime}}^{*}(\varnothing)\right) .
$$

Thus, whenever $s_{\chi^{\prime}} \in S_{x^{\prime}}^{\varnothing}\left(X^{\prime \prime}\right)$, i.e., $V\left(x^{\prime} \mid s_{x^{\prime}}, s_{x^{\prime}}, X^{\prime \prime}\right)<V\left(x^{\prime} \mid s_{x^{\prime}}, \varnothing, X^{\prime \prime}\right)$, we must also have

$$
V\left(x^{\prime} \mid s_{x^{\prime}}, s_{x^{\prime}}, X^{\prime}\right)<V\left(x^{\prime} \mid s_{x^{\prime}}, \varnothing, X^{\prime}\right) \text {. }
$$

That is, the DM also suppresses $s_{X^{\prime}}$ under $X^{\prime}$. Hence, $S_{X^{\prime}}^{\varnothing}\left(X^{\prime \prime}\right) \subset S_{X^{\prime}}^{\varnothing}\left(X^{\prime}\right)$. 


\section{A5. Proof of Proposition 5}

From Lemmas 1 and 2, $S_{\chi^{\prime}}^{\varnothing}(X) \subset S_{\chi^{\prime}}^{d}(X)$ and $S_{\chi^{\prime}}^{\varnothing}\left(X^{\prime \prime}\right) \subset S_{\chi^{\prime}}^{\varnothing}\left(X^{\prime}\right)$. We also know that $S_{\chi^{\prime}}^{d}\left(X^{\prime \prime}\right) \subset S_{\chi^{\prime}}^{d}\left(X^{\prime}\right)$. Then, consider the following six possible cases to establish Proposition 5.

First, if $s_{X^{\prime}} \notin S_{\chi^{\prime}}^{d}\left(X^{\prime}\right)$, then $\psi_{X}^{*}\left(s_{X^{\prime}} ; X^{\prime}\right)=s_{X^{\prime}}$ and the DM experiences no dissonance under both choice sets. Hence,

$$
V\left(x^{\prime} \mid s_{X^{\prime}}, \psi_{X}^{*}\left(s_{X^{\prime}} ; X^{\prime}\right), X^{\prime}\right)=V\left(x^{\prime} \mid s_{X^{\prime}}, \psi_{X}^{*}\left(s_{X^{\prime}} ; X^{\prime \prime}\right), X^{\prime \prime}\right)=U\left(x^{\prime} \mid s_{X^{\prime}}\right) .
$$

Second, if $\left.s_{X^{\prime}} \in\left(S_{X^{\prime}}^{d}\left(X^{\prime}\right) \backslash S_{X^{\prime}}^{\varnothing}\left(X^{\prime}\right)\right)\right) \cap\left(S_{X^{\prime}}^{d}\left(X^{\prime \prime}\right) \backslash S_{X^{\prime}}^{\varnothing}\left(X^{\prime \prime}\right)\right)$, then $\psi_{X}^{*}\left(s_{X^{\prime}} ; X^{\prime}\right)=S_{X^{\prime}}$ and the DM experiences dissonance under both choice sets. Then, since $\gamma_{X^{\prime}}\left(s_{X^{\prime}} ; X^{\prime}\right) \geq \gamma_{X^{\prime}}\left(s_{X^{\prime}} ; X^{\prime \prime}\right)$,

$$
V\left(x^{\prime} \mid s_{X^{\prime}}, \psi_{X}^{*}\left(s_{X^{\prime}} ; X^{\prime}\right), X^{\prime}\right)=U\left(x^{\prime} \mid s_{X^{\prime}}\right)-\gamma_{x^{\prime}}\left(s_{X^{\prime}} ; X^{\prime}\right) \leq V\left(x^{\prime} \mid s_{X^{\prime}}, \psi_{X}^{*}\left(s_{X^{\prime}} ; X^{\prime \prime}\right), X^{\prime \prime}\right)=U\left(x^{\prime} \mid s_{X^{\prime}}\right)-\gamma_{X^{\prime}}\left(s_{X^{\prime}} ; X^{\prime \prime}\right) \text {. }
$$

Third, if $s_{X^{\prime}} \in S_{X^{\prime}}^{d}\left(X^{\prime \prime}\right) \cap\left(S_{X^{\prime}}^{\varnothing}\left(X^{\prime}\right) \backslash S_{X^{\prime}}^{\varnothing}\left(X^{\prime \prime}\right)\right)$, then $\psi_{X}^{*}\left(s_{x^{\prime}} ; X^{\prime}\right)=\varnothing$ and $\psi_{X}^{*}\left(s_{X^{\prime}} ; X^{\prime \prime}\right)=s_{X^{\prime}}$. Thus,

$$
V\left(x^{\prime} \mid s_{x^{\prime}}, \varnothing, X^{\prime}\right)=\sum_{\theta_{x^{\prime}}} f\left(e_{x^{\prime}}^{*}(\varnothing), \theta_{x^{\prime}}\right) p\left(\theta_{x^{\prime}} \mid s_{x^{\prime}}\right)-c\left(e_{x^{\prime}}^{*}(\varnothing)\right)>U\left(x^{\prime} \mid s_{x^{\prime}}\right)-\gamma_{x^{\prime}}\left(s_{X^{\prime}} ; X^{\prime}\right)
$$

On the other hand, since $s_{X^{\prime}} \in S_{X^{\prime}}^{d}\left(X^{\prime \prime}\right) \backslash S_{X^{\prime}}^{\varnothing}\left(X^{\prime \prime}\right)$,

$$
U\left(x^{\prime} \mid s_{X^{\prime}}\right)-\gamma_{x^{\prime}}\left(s_{x^{\prime}} ; X^{\prime \prime}\right)>V\left(x^{\prime} \mid s_{X^{\prime}}, \varnothing, X^{\prime \prime}\right) .
$$

Note that $V\left(x^{\prime} \mid s_{\chi^{\prime}}, \varnothing, X^{\prime \prime}\right)=V\left(x^{\prime} \mid s_{x^{\prime}}, \varnothing, X^{\prime}\right)$. Thus, $V\left(x^{\prime} \mid s_{x^{\prime}}, \psi_{x^{\prime}}\left(s_{\chi^{\prime}} ; X^{\prime \prime}\right), X^{\prime \prime}\right)>V\left(x^{\prime} \mid s_{x^{\prime}}, \psi_{x^{\prime}}\left(s_{x^{\prime}} ; X^{\prime}\right), X^{\prime}\right)$.

Fourth, when $s_{X^{\prime}} \in S_{x^{\prime}}^{\varnothing}\left(X^{\prime}\right)$ but $s_{X^{\prime}} \notin S_{x^{\prime}}^{d}\left(X^{\prime \prime}\right)$, then $\psi_{X}^{*}\left(s_{X^{\prime}} ; X^{\prime}\right)=\varnothing$ and $\psi_{X}^{*}\left(s_{X^{\prime}} ; X^{\prime \prime}\right)=s_{X^{\prime}}$. Since $s_{X^{\prime}} \notin S_{x^{\prime}}^{d}\left(X^{\prime \prime}\right)$, we have $V\left(x^{\prime} \mid s_{X^{\prime}}, \psi_{X^{\prime}}\left(s_{X^{\prime}} ; X^{\prime \prime}\right), X^{\prime \prime}\right)=U\left(x^{\prime} \mid s_{X^{\prime}}\right)$. Hence, $V\left(x^{\prime} \mid s_{X^{\prime}}, \psi_{X^{\prime}}\left(s_{X^{\prime}} ; X^{\prime \prime}\right), X^{\prime \prime}\right)>V\left(x^{\prime} \mid s_{X^{\prime}}, \psi_{X^{\prime}}\left(s_{X^{\prime}} ; X^{\prime}\right), X^{\prime}\right)$.

Fifth, if $s_{X} \in S_{X^{\prime}}^{\varnothing}\left(X^{\prime \prime}\right)$, then $\psi_{X}^{*}\left(s_{X^{\prime}} ; X^{\prime}\right)=\psi_{X}^{*}\left(s_{X^{\prime}} ; X^{\prime \prime}\right)=\varnothing$. Thus,

$$
V\left(x^{\prime} \mid s_{x^{\prime}}, \psi_{x^{\prime}}\left(s_{x^{\prime}} ; X^{\prime}\right), X^{\prime}\right)=V\left(x^{\prime} \mid s_{x^{\prime}}, \psi_{x^{\prime}}\left(s_{x^{\prime}} ; X^{\prime \prime}\right), X^{\prime \prime}\right)=\sum_{\theta_{x^{\prime}}} f\left(e_{x^{\prime}}^{*}(\varnothing), \theta_{x^{\prime}}\right) p\left(\theta_{x^{\prime}} \mid s_{x^{\prime}}\right)-c\left(e_{x^{\prime}}^{*}(\varnothing)\right) .
$$

Lastly, if $s_{X^{\prime}} \in S_{X^{\prime}}^{d}\left(X^{\prime}\right) \backslash\left(S_{X^{\prime}}^{d}\left(X^{\prime \prime}\right) \cup S_{X^{\prime}}^{\varnothing}\left(X^{\prime}\right)\right)$, then $\psi_{x}^{*}\left(s_{X^{\prime}} ; X^{\prime}\right)=\psi_{X}^{*}\left(s_{X^{\prime}} ; X^{\prime \prime}\right)=s_{X^{\prime}}$. Note that the DM does not experience dissonance under $X^{\prime \prime}$, whereas the DM experiences dissonance under $X^{\prime}$. Thus,

$$
V\left(x^{\prime} \mid s_{X^{\prime}}, \psi_{X^{\prime}}\left(s_{X^{\prime}} ; X^{\prime \prime}\right), X^{\prime \prime}\right)=U\left(x^{\prime} \mid s_{X^{\prime}}\right)>V\left(x^{\prime} \mid s_{X^{\prime}}, \psi_{X^{\prime}}\left(s_{X^{\prime}} ; X^{\prime}\right), X^{\prime}\right)=U\left(x^{\prime} \mid s_{X^{\prime}}\right)-\gamma_{X^{\prime}}\left(s_{X^{\prime}} ; X^{\prime}\right) .
$$

By summarizing all the cases, $V^{*}\left(x^{\prime} ; X^{\prime \prime}\right) \geq V^{*}\left(x^{\prime} ; X^{\prime}\right)$.

\section{A6. Proof of Lemma 3}

Suppose $s_{x^{\prime}} \in S_{x^{\prime}}^{\varnothing}\left(\left\{x^{\prime}, x^{\prime \prime \prime}\right\}\right)$. If all signals in $S_{x^{\prime}}$ are project-specific, then $U\left(x^{\prime \prime}\right)=U\left(x^{\prime \prime} \mid s_{x^{\prime}}\right)$ and $U\left(x^{\prime \prime \prime}\right)=U\left(x^{\prime \prime \prime} \mid s_{x^{\prime}}\right)$ for all $s_{x^{\prime}}$. Hence, if $U\left(x^{\prime \prime}\right)>U(x / \prime \prime)$ and all signals in $S_{x^{\prime}}$ are project-specific, then $U\left(x^{\prime \prime} \mid s_{x^{\prime}}\right)>U\left(x^{\prime} \mid s_{x^{\prime}}\right)$ whenever $U\left(x^{\prime \prime \prime} \mid s_{x^{\prime}}\right)>U\left(x^{\prime} \mid s_{x^{\prime}}\right)$. Thus, if $s_{x^{\prime}} \in S_{x^{\prime}}^{d}\left(\left\{x^{\prime}, x^{\prime \prime \prime}\right\}\right)$, then $s_{x^{\prime}} \in S_{x^{\prime}}^{d}\left(\left\{x^{\prime}, x^{\prime \prime}\right\}\right)$ and $\gamma_{x^{\prime}}\left(s_{x^{\prime}} ;\left\{x^{\prime}, x^{\prime \prime}\right\}\right) \geq \gamma_{x^{\prime}}\left(s_{x^{\prime}} ;\left\{x^{\prime}, x^{\prime \prime \prime}\right\}\right)$. It follows that

$$
V\left(x^{\prime} \mid s_{x^{\prime}}, s_{x^{\prime}},\left\{x^{\prime}, x^{\prime \prime}\right\}\right)=U\left(x^{\prime} \mid s_{x^{\prime}}\right)-\gamma_{x^{\prime}}\left(s_{x^{\prime}} ;\left\{x^{\prime}, x^{\prime \prime}\right\}\right) \leq V\left(x^{\prime} \mid s_{x^{\prime}}, s_{x^{\prime}},\left\{x^{\prime}, x^{\prime \prime \prime}\right\}\right)=U\left(x^{\prime} \mid s_{x^{\prime}}\right)-\gamma_{x^{\prime}}\left(s_{x^{\prime}} ;\left\{x^{\prime}, x^{\prime \prime \prime}\right\}\right) \text {. }
$$

Now observe

$$
V\left(x^{\prime} \mid s_{x^{\prime}}, \varnothing,\left\{x^{\prime}, x^{\prime \prime}\right\}\right)=V\left(x^{\prime} \mid s_{x^{\prime}}, \varnothing,\left\{x^{\prime}, x^{\prime \prime \prime}\right\}\right)=\sum_{\theta_{x^{\prime}}} f\left(e_{x^{\prime}}^{*}(\varnothing), \theta_{x^{\prime}}\right) p\left(\theta_{x^{\prime}} \mid s_{x^{\prime}}\right)-c\left(e_{x^{\prime}}^{*}(\varnothing)\right)
$$

Thus, if $s_{x^{\prime}} \in S_{x^{\prime}}^{\varnothing}\left(\left\{x^{\prime}, x^{\prime \prime \prime}\right\}\right)$, i.e., $V\left(x^{\prime} \mid s_{x^{\prime}}, \varnothing,\left\{x^{\prime}, x^{\prime \prime \prime}\right\}\right)>V\left(x^{\prime} \mid s_{x^{\prime}}, s_{x^{\prime}},\left\{x^{\prime}, x^{\prime \prime \prime}\right\}\right)$, then we also have

$$
V\left(x^{\prime} \mid s_{x^{\prime}}, \varnothing,\left\{x^{\prime}, x^{\prime \prime}\right\}\right)>V\left(x^{\prime} \mid s_{x^{\prime}}, s_{x^{\prime}},\left\{x^{\prime}, x^{\prime \prime}\right\}\right) .
$$

Hence, $S_{x^{\prime}}^{\varnothing}\left(\left\{x^{\prime}, x^{\prime \prime \prime}\right\}\right) \subset S_{x^{\prime}}^{\varnothing}\left(\left\{x^{\prime}, x^{\prime \prime}\right\}\right)$.

\section{A7. Proof of Proposition 7}

As it is shown in the proof of Lemma 3, if all signals are project-specific and $U\left(x^{\prime \prime}\right)>U\left(x^{\prime \prime \prime}\right)$, then $S_{x^{\prime}}^{d}\left(\left\{x^{\prime}, x^{\prime \prime \prime}\right\}\right) \subset$ $S_{x^{\prime}}^{d}\left(\left\{x^{\prime}, x^{\prime \prime}\right\}\right)$. Moreover, from Lemmas 1 and $3, S_{x^{\prime}}^{\varnothing}\left(\left\{x^{\prime}, x^{\prime \prime}\right\}\right) \subset S_{x^{\prime}}^{d}\left(\left\{x^{\prime}, x^{\prime \prime}\right\}\right)$ and $S_{x^{\prime}}^{\varnothing}\left(\left\{x^{\prime}, x^{\prime \prime \prime}\right\}\right) \subset S_{x^{\prime}}^{\varnothing}\left(\left\{x^{\prime}, x^{\prime \prime}\right\}\right)$. Thus, consider the following six possible cases to prove Proposition 7 .

First, if $s_{x^{\prime}} \notin S_{x^{\prime}}^{d}\left(\left\{x^{\prime}, x^{\prime \prime}\right\}\right)$, then the DM experiences no dissonance under both choice sets. Hence,

$$
V\left(x^{\prime} \mid s_{x^{\prime}}, \psi_{x}^{*}\left(s_{x^{\prime}} ;\left\{x^{\prime}, x^{\prime \prime}\right\}\right),\left\{x^{\prime}, x^{\prime \prime}\right\}\right)=V\left(x^{\prime} \mid s_{x^{\prime}}, \psi_{x}^{*}\left(s_{x^{\prime}} ;\left\{x^{\prime}, x^{\prime \prime \prime}\right\}\right),\left\{x^{\prime}, x^{\prime \prime \prime}\right\}\right)=U\left(x^{\prime} \mid s_{x^{\prime}}\right) .
$$

Second, if $\left.s_{x^{\prime}} \in\left(S_{x^{\prime}}^{d}\left(\left\{x^{\prime}, x^{\prime \prime}\right\}\right) \backslash S_{x^{\prime}}^{\varnothing}\left(\left\{x^{\prime}, x^{\prime \prime}\right\}\right)\right)\right) \cap\left(S_{x^{\prime}}^{d}\left(\left\{x^{\prime}, x^{\prime \prime \prime}\right\}\right) \backslash S_{x^{\prime}}^{\varnothing}\left(\left\{x^{\prime}, x^{\prime \prime \prime}\right\}\right)\right)$, then $\psi_{x}^{*}\left(s_{x^{\prime}} ;\left\{x^{\prime}, x^{\prime \prime}\right\}\right)=s_{x^{\prime}}$ and the DM suffers from dissonance under both choice sets. Since $\gamma_{x^{\prime}}\left(s_{x^{\prime}} ;\left\{x^{\prime}, x^{\prime \prime}\right\}\right) \geq \gamma_{x^{\prime}}\left(s_{x^{\prime}} ;\left\{x^{\prime}, x^{\prime \prime \prime}\right\}\right)$,

$$
V\left(x^{\prime} \mid s_{x^{\prime}}, \psi_{x}^{*}\left(s_{x^{\prime}} ;\left\{x^{\prime}, x^{\prime \prime}\right\}\right),\left\{x^{\prime}, x^{\prime \prime}\right\}\right) \leq V\left(x^{\prime} \mid s_{x^{\prime}}, \psi_{x}^{*}\left(s_{x^{\prime}} ;\left\{x^{\prime}, x^{\prime \prime \prime}\right\}\right),\left\{x^{\prime}, x^{\prime \prime \prime}\right\}\right) .
$$


Third, if $s_{x^{\prime}} \in S_{x^{\prime}}^{d}\left(\left\{x^{\prime}, x^{\prime \prime \prime}\right\}\right) \cap\left(S_{x^{\prime}}^{\varnothing}\left(\left\{x^{\prime}, x^{\prime \prime}\right\}\right) \backslash S_{x^{\prime}}^{\varnothing}\left(\left\{x^{\prime}, x^{\prime \prime \prime}\right\}\right)\right)$, then $\psi_{x}^{*}\left(s_{x^{\prime}} ;\left\{x^{\prime}, x^{\prime \prime}\right\}\right)=\varnothing$ and $\psi_{x}^{*}\left(s_{x^{\prime}} ;\left\{x^{\prime}, x^{\prime \prime \prime}\right\}\right)=s_{x^{\prime}}$. Thus, the DM prefers to suppress the signal under $\left\{x^{\prime}, x^{\prime \prime}\right\}$, i.e.,

$$
V\left(x^{\prime} \mid s_{x^{\prime}}, \varnothing,\left\{x^{\prime}, x^{\prime \prime}\right\}\right)=\sum_{\theta_{x^{\prime}}} f\left(e_{x^{\prime}}^{*}(\varnothing), \theta_{x^{\prime}}\right) p\left(\theta_{x^{\prime}} \mid s_{x^{\prime}}\right)-c\left(e_{x^{\prime}}^{*}(\varnothing)\right)>U\left(x^{\prime} \mid s_{x^{\prime}}\right)-\gamma_{x^{\prime}}\left(s_{x^{\prime}} ;\left\{x^{\prime}, x^{\prime \prime}\right\}\right)
$$

On the other hand, since $s_{x^{\prime}} \in S_{x^{\prime}}^{d}\left(\left\{x^{\prime}, x^{\prime \prime \prime}\right\}\right) \backslash S_{x^{\prime}}^{\varnothing}\left(\left\{x^{\prime}, x^{\prime \prime \prime}\right\}\right)$,

$$
U\left(x^{\prime} \mid s_{x^{\prime}}\right)-\gamma_{x^{\prime}}\left(s_{x^{\prime}} ;\left\{x^{\prime}, x^{\prime \prime \prime}\right\}\right)>V\left(x^{\prime} \mid s_{x^{\prime}}, \varnothing,\left\{x^{\prime}, x^{\prime \prime \prime}\right\}\right) \text {. }
$$

Note that $V\left(x^{\prime} \mid s_{x^{\prime}}, \varnothing,\left\{x^{\prime}, x^{\prime \prime \prime}\right\}\right)=V\left(x^{\prime} \mid s_{x^{\prime}}, \varnothing,\left\{x^{\prime}, x^{\prime \prime}\right\}\right)$. Thus,

$$
V\left(x^{\prime} \mid s_{x^{\prime}}, \psi_{x^{\prime}}\left(s_{x^{\prime}} ;\left\{x^{\prime}, x^{\prime \prime \prime}\right\}\right),\left\{x^{\prime}, x^{\prime \prime \prime}\right\}\right)>V\left(x^{\prime} \mid s_{x^{\prime}}, \psi_{x^{\prime}}\left(s_{x^{\prime}} ;\left\{x^{\prime}, x^{\prime \prime}\right\}\right),\left\{x^{\prime}, x^{\prime \prime}\right\}\right) \text {. }
$$

Fourth, if $s_{x^{\prime}} \in S_{x^{\prime}}^{\varnothing}\left(\left\{x^{\prime}, x^{\prime \prime}\right\}\right)$ but $s_{x^{\prime}} \notin S_{x^{\prime}}^{d}\left(\left\{x^{\prime}, x^{\prime \prime \prime}\right\}\right)$, then $\psi_{x}^{*}\left(s_{x^{\prime}} ;\left\{x^{\prime}, x^{\prime \prime}\right\}\right)=\varnothing$ and $\psi_{x}^{*}\left(s_{x^{\prime}} ;\left\{x^{\prime}, x^{\prime \prime \prime}\right\}\right)=s_{x^{\prime}}$. Since $s_{x^{\prime}} \notin$ $S_{x^{\prime}}^{d}\left(\left\{x^{\prime}, x^{\prime \prime \prime}\right\}\right)$, we have $V\left(x^{\prime} \mid s_{x^{\prime}}, \psi_{x^{\prime}}\left(s_{x^{\prime}} ;\left\{x^{\prime}, x^{\prime \prime \prime}\right\}\right),\left\{x^{\prime}, x^{\prime \prime \prime}\right\}\right)=U\left(x^{\prime} \mid s_{x^{\prime}}\right)$. Hence,

$V\left(x^{\prime} \mid s_{x^{\prime}}, \psi_{x^{\prime}}\left(s_{x^{\prime}} ;\left\{x^{\prime}, x^{\prime \prime \prime}\right\}\right),\left\{x^{\prime}, x^{\prime \prime \prime}\right\}\right)>V\left(x^{\prime} \mid s_{x^{\prime}}, \psi_{x^{\prime}}\left(s_{x^{\prime}} ;\left\{x^{\prime}, x^{\prime \prime}\right\}\right),\left\{x^{\prime}, x^{\prime \prime}\right\}\right)$.

Fifth, if $s_{X} \in S_{x^{\prime}}^{\varnothing}\left(\left\{x^{\prime}, x^{\prime \prime \prime}\right\}\right)$, then $\psi_{x}^{*}\left(s_{x^{\prime}} ;\left\{x^{\prime}, x^{\prime \prime}\right\}\right)=\psi_{x}^{*}\left(s_{x^{\prime}} ;\left\{x^{\prime}, x^{\prime \prime \prime}\right\}\right)=\varnothing$. Thus,

$$
V\left(x^{\prime} \mid s_{x^{\prime}}, \psi_{x^{\prime}}\left(s_{x^{\prime}} ;\left\{x^{\prime}, x^{\prime \prime}\right\}\right),\left\{x^{\prime}, x^{\prime \prime}\right\}\right)=V\left(x^{\prime} \mid s_{x^{\prime}}, \psi_{x^{\prime}}\left(s_{x^{\prime}} ;\left\{x^{\prime}, x^{\prime \prime \prime}\right\}\right),\left\{x^{\prime}, x^{\prime \prime \prime}\right\}\right) \text {. }
$$

Finally, if $s_{x^{\prime}} \in S_{x^{\prime}}^{d}\left(\left\{x^{\prime}, x^{\prime \prime}\right\}\right) \backslash\left(S_{x^{\prime}}^{d}\left(\left\{x^{\prime}, x^{\prime \prime \prime}\right\}\right) \cup S_{x^{\prime}}^{\varnothing}\left(\left\{x^{\prime}, x^{\prime \prime}\right\}\right)\right)$, then $\psi_{x}^{*}\left(s_{x^{\prime}} ;\left\{x^{\prime}, x^{\prime \prime}\right\}\right)=\psi_{x}^{*}\left(s_{x^{\prime}} ;\left\{x^{\prime}, x^{\prime \prime \prime}\right\}\right)=s_{x^{\prime}}$. Note that the DM does not experience dissonance under $\left\{x^{\prime}, x^{\prime \prime \prime}\right\}$, whereas the DM experiences dissonance under $\left\{x^{\prime}, x^{\prime \prime}\right\}$. Thus,

$$
V\left(x^{\prime} \mid s_{x^{\prime}}, \psi_{x^{\prime}}\left(s_{x^{\prime}} ;\left\{x^{\prime}, x^{\prime \prime \prime}\right\}\right),\left\{x^{\prime}, x^{\prime \prime \prime}\right\}\right)=U\left(x^{\prime} \mid s_{x^{\prime}}\right)>V\left(x^{\prime} \mid s_{x^{\prime}}, \psi_{x^{\prime}}\left(s_{x^{\prime}} ;\left\{x^{\prime}, x^{\prime \prime}\right\}\right),\left\{x^{\prime}, x^{\prime \prime}\right\}\right) .
$$

From the above cases, we obtain $V^{*}\left(x^{\prime} ;\left\{x^{\prime}, x^{\prime \prime \prime}\right\}\right) \geq V^{*}\left(x^{\prime} ;\left\{x^{\prime}, x^{\prime \prime}\right\}\right)$.

\section{A8. Proof of Proposition 9}

From Proposition 4, given $x, y_{x \mid X}^{*} \geq y_{x \mid Z}^{*}$ if $Z \subset X$. Thus, by the definition of $x^{\prime}$, the performance of project $x^{\prime}$ chosen from $X$ is higher than that of any other project chosen from any choice set $Z \subset X$.

Now suppose $\psi_{X^{\prime}}\left(s_{X^{\prime}} ; X\right)=s_{X^{\prime}}$ for all $s_{X^{\prime}} \in S_{X^{\prime}}^{d}(X)$. Then, the DM suffers from any dissonant signal in $S_{X^{\prime}}^{d}(X)$. Hence, the dissonance-adjusted expected utility from $X^{\prime}$ given $\psi_{X^{\prime}}$ is

$$
U\left(x^{\prime}\right)-\sum_{s_{x^{\prime}}} \gamma_{x^{\prime}}\left(s_{X^{\prime}} ; X\right) p\left(s_{X^{\prime}}\right)
$$

Since $V^{*}\left(x^{\prime} ; X\right)$ is based on the optimal $\psi^{*}$,

$$
V^{*}\left(x^{\prime} ; X\right) \geq U\left(x^{\prime}\right)-\sum_{s_{x^{\prime}}} \gamma_{x^{\prime}}\left(s_{x^{\prime}} ; X\right) p\left(s_{x^{\prime}}\right) \text {. }
$$

If the condition in Proposition 9 holds,

$$
U\left(x^{\prime}\right)-\sum_{s_{x^{\prime}}} \gamma_{x^{\prime}}\left(s_{x^{\prime}} ; X\right) p\left(s_{x^{\prime}}\right)>U(x)
$$

for all $x \in X \backslash\left\{x^{\prime}\right\}$. Then, since $V^{*}(x ; X) \leq U(x)$ for all $x$ from Proposition $2, V^{*}\left(x^{\prime} ; X\right)>V^{*}(x ; X)$ for all $x \in X \backslash\left\{x^{\prime}\right\}$. The DM then selects the output maximizing project $x^{\prime}$ from $X$. Thus, $X$ is an output-maximizing choice set.

\section{A9. Proof of Proposition 10}

Before proving Proposition 10, I introduce two basic properties of information processing rules. An information rule is admissible if $\phi_{X}\left(s_{X} ; X\right)=s_{X}$ whenever $s_{X} \notin S_{X}^{d}(X)$. An information rule is choice set monotonic if, for any $s_{X} \in S_{X}^{d}(X) \cap S_{X}^{d}\left(X^{\prime}\right)$, $\phi_{X}\left(s_{X} ; X\right) \leq \phi_{X}\left(s_{X} ; X^{\prime}\right)$ whenever $X \subset X^{\prime}$.

Claim 1. Suppose $\gamma_{x}$ has weakly increasing difference property. If $X \subset X^{\prime}$, then there exists optimal information processing rules $\phi_{X}(. ; X)$ and $\phi_{X}\left(. ; X^{\prime}\right)$ that are admissible and choice set monotonic.

First, if a signal is not dissonant, the DM has no reason to distort her perception as it only reduces her utility. Thus, any optimal rule is admissible.

Second, consider a signal $s_{X} \in S_{X}^{d}(X) \cap S_{X}^{d}\left(X^{\prime}\right)$. Note that

$$
V\left(x \mid s_{x}, \phi_{x}\left(s_{x} ; X\right), X\right)=\sum_{\theta_{x}} f\left(e_{x}^{*}\left(\phi_{x}\left(s_{x} ; X\right)\right), \theta_{x}\right) p\left(\theta_{x} \mid s_{x}\right)-c\left(e_{x}^{*}\left(\phi_{x}\left(s_{x} ; X\right)\right)\right)-\gamma_{x}\left(\phi_{x}\left(s_{x} ; X\right) ; X\right)
$$

Thus, if $\phi_{X}\left(s_{X} ; X\right)$ and $\phi_{X}\left(s_{X} ; X^{\prime}\right)$ are optimal rules,

$$
\begin{aligned}
& \sum_{\theta_{x}} f\left(e_{x}^{*}\left(\phi_{x}\left(s_{x} ; X\right)\right), \theta_{x}\right) p\left(\theta_{x} \mid s_{x}\right)-c\left(e_{x}^{*}\left(\phi_{x}\left(s_{x} ; X\right)\right)\right)-\gamma_{x}\left(\phi_{x}\left(s_{x} ; X\right) ; X\right) \\
& \geq \sum_{\theta_{x}} f\left(e_{x}^{*}\left(\phi_{x}\left(s_{x} ; X^{\prime}\right)\right), \theta_{x}\right) p\left(\theta_{x} \mid s_{x}\right)-c\left(e_{x}^{*}\left(\phi_{x}\left(s_{x} ; X^{\prime}\right)\right)\right)-\gamma_{x}\left(\phi_{x}\left(s_{x} ; X^{\prime}\right) ; X\right)
\end{aligned}
$$


and

$$
\begin{aligned}
& \sum_{\theta_{x}} f\left(e_{x}^{*}\left(\phi_{x}\left(s_{x} ; X^{\prime}\right)\right), \theta_{x}\right) p\left(\theta_{x} \mid s_{x}\right)-c\left(e_{x}^{*}\left(\phi_{x}\left(s_{x} ; X^{\prime}\right)\right)\right)-\gamma_{x}\left(\phi_{x}\left(s_{x} ; X^{\prime}\right) ; X^{\prime}\right) \\
& \quad \geq \sum_{\theta_{x}} f\left(e_{x}^{*}\left(\phi_{x}\left(s_{x} ; X\right)\right), \theta_{x}\right) p\left(\theta_{x} \mid s_{x}\right)-c\left(e_{x}^{*}\left(\phi_{x}\left(s_{x} ; X\right)\right)\right)-\gamma_{x}\left(\phi_{x}\left(s_{x} ; X\right) ; X^{\prime}\right)
\end{aligned}
$$

Let

$$
\begin{gathered}
\Delta=\sum_{\theta_{x}} f\left(e_{x}^{*}\left(\phi_{x}\left(s_{x} ; X^{\prime}\right)\right), \theta_{x}\right) p\left(\theta_{x} \mid s_{x}\right)-c\left(e_{x}^{*}\left(\phi_{x}\left(s_{x} ; X^{\prime}\right)\right)\right) \\
-\sum_{\theta_{x}}\left[f\left(e_{x}^{*}\left(\phi_{x}\left(s_{x} ; X\right)\right), \theta_{x}\right) p\left(\theta_{x} \mid s_{x}\right)-c\left(e_{x}^{*}\left(\phi_{x}\left(s_{x} ; X\right)\right)\right)\right]
\end{gathered}
$$

Then, the inequality conditions can be written as

$$
\gamma_{x}\left(\phi_{x}\left(s_{x} ; X^{\prime}\right) ; X\right)-\gamma_{x}\left(\phi_{x}\left(s_{x} ; X\right) ; X\right) \geq \Delta \geq \gamma_{x}\left(\phi_{x}\left(s_{x} ; X^{\prime}\right) ; X^{\prime}\right)-\gamma_{x}\left(\phi_{x}\left(s_{x} ; X\right) ; X^{\prime}\right)
$$

Suppose there exists a unique optimal rule under $X^{\prime}$, which is not choice set monotonic, i.e., $\phi_{x}\left(s_{X} ; X^{\prime}\right)<\phi_{x}\left(s_{X} ; X\right)$. If the dissonance function has weakly increasing difference property, the above inequality holds only if

$$
\gamma_{x}\left(\phi_{x}\left(s_{x} ; X^{\prime}\right) ; X\right)-\gamma_{x}\left(\phi_{x}\left(s_{x} ; X\right) ; X\right)=\Delta=\gamma_{x}\left(\phi_{x}\left(s_{x} ; X^{\prime}\right) ; X^{\prime}\right)-\gamma_{x}\left(\phi_{x}\left(s_{x} ; X\right) ; X^{\prime}\right)
$$

But then processing $s_{X}$ based on $\phi_{x}\left(s_{X} ; X\right)$ under $X^{\prime}$ is also optimal. That is, whenever an optimal information processing rule under $X^{\prime}$ is non monotonic, there is another optimal information processing rule that is monotonic.

Turning to the proof of Proposition 10, note that $S_{X}^{d}(X) \subset S_{X}^{d}\left(X^{\prime}\right)$. Hence, we need to consider the following three cases.

First, if $s_{X} \notin S_{X}^{d}\left(X^{\prime}\right), \phi_{X}\left(s_{X} ; X\right)=\phi_{X}\left(s_{x} ; X^{\prime}\right)=s_{X}$ from admissibility. Thus, for all $\theta_{x}$,

$$
f\left(e_{X}^{*}\left(\phi_{X}\left(s_{X} ; X^{\prime}\right)\right), \theta_{X}\right)=f\left(e_{X}^{*}\left(\phi_{X}\left(s_{X} ; X\right)\right), \theta_{X}\right) .
$$

Second, if $s_{X} \in S_{X}^{d}\left(X^{\prime}\right) \backslash S_{X}^{d}(X)$, then $\phi_{x}\left(s_{X} ; X\right)=s_{X}$. If $\gamma_{X}$ is weakly decreasing in $s_{X}$, clearly $\phi_{x}\left(s_{X} ; X^{\prime}\right) \geq s_{X}$. Then, since $e_{x}^{*}$ is increasing in $s_{X}$, and $f$ is also increasing in $e$,

$$
f\left(e_{x}^{*}\left(\phi_{x}\left(s_{x} ; X^{\prime}\right)\right), \theta_{x}\right) \geq f\left(e_{x}^{*}\left(\phi_{x}\left(s_{x} ; X\right)\right), \theta_{x}\right)
$$

for all $\theta_{x}$.

Finally, if $s_{X} \in S_{X}^{d}(X)$, the choice set monotonicity implies $\phi_{X}\left(s_{X} ; X^{\prime}\right) \geq \phi_{X}\left(s_{X} ; X\right)$. Then, since $e_{X}^{*}\left(s_{X}\right)$ is increasing in $s_{X}$ and $f$ is also increasing in $e$,

$$
f\left(e_{x}^{*}\left(\phi_{x}\left(s_{x} ; X^{\prime}\right)\right), \theta_{x}\right) \geq f\left(e_{x}^{*}\left(\phi_{x}\left(s_{x} ; X\right)\right), \theta_{x}\right) .
$$

for all $\theta_{x}$. Now recall that

$$
y_{x \mid X}^{*}=\sum_{\theta_{x}} \sum_{s_{x}} f\left(e_{x}^{*}\left(\phi_{x}\left(s_{x} ; X^{\prime}\right)\right), \theta_{x}\right) p\left(s_{x}, \theta_{x}\right)
$$

Thus, $y_{x \mid X^{\prime}}^{*} \geq y_{x \mid X}^{*}$.

\section{References}

Akerlof, G.A., Dickens, W.T., 1982. The economic consequences of cognitive dissonance. Am. Econ. Rev. 72 (3), $307-319$.

Bell, D.E., 1982. Regret in decision making under uncertainty. Oper. Res. 30 (5), 961-981.

Bénabou, R., Tirole, J., 2002. Self-confidence and personal motivation. Quart. J. Econ. 117 (3), 871-915.

Benabou, R., Tirole, J., 2003. Intrinsic and extrinsic motivation. Rev.Econ. Stud. 70 (3), 489-520.

Brehm, J.W., 1956. Postdecision changes in the desirability of alternatives. J. Abnorm. Soc. Psychol. 52 (3), 384.

Brunnermeier, M.K., Parker, J.A., 2005. Optimal expectations. Am. Econ. Rev. 95 (4), 1092-1118.

Canon, L.K., 1964. Self-confidence and selective exposure to information. Confl. Decis. Dissonance 1, 83-95.

Charness, G., Cobo-Reyes, R., Jiménez, N., Lacomba, J.A., Lagos, F., 2012. The hidden advantage of delegation: Pareto improvements in a gift exchange game. Am. Econ. Rev. 102 (5), 2358-2379.

Compte, O., Postlewaite, A., 2004. Confidence-enhanced performance. Am. Econ. Rev. 94 (5), 1536-1557.

Cordova, D.I., Lepper, M.R., 1996. Intrinsic motivation and the process of learning: beneficial effects of contextualization, personalization, and choice. J. Educ. Psychol. 88 (4), 715.

De Clippel, G., Eliaz, K., 2012. Reason-based choice: a bargaining rationale for the attraction and compromise effects. Theor. Econ. 7 (1), $125-162$.

Deci, E., Ryan, R., 1985. Intrinsic motivation and self-determination in motivation. Plenum, New York.

Elkin, R.A., Leippe, M.R., 1986. Physiological arousal, dissonance, and attitude change: evidence for a dissonance-arousal link and a" don't remind me" effect.. J. Personal. Soc. Psychol. 51 (1), 55.

Eyster, E., 2002. Rationalizing the Past: A Taste for Consistency. Nuffield College Mimeograph

Falk, A., Kosfeld, M., 2006. The hidden costs of control. Am. Econ. Rev. 96 (5), 1611-1630.

Festinger, L., 1957. A Theory of Cognitive Dissonance. Stanford University Press.

Freedman, J.L., 1965. Confidence, utility, and selective exposure: apartial replication. J.Personal.Soc.Psychol. 2 (5), 778.

Gneezy, U., Rustichini, A., 2000. A fine is a price. J. Legal Stud. 29 (1), 1-17.

Gul, F., Pesendorfer, W., 2001. Temptation and self-control. Econometrica 69 (6), 1403-1435.

Hardyck, J.A., Kardush, M., 1968. A modest modish model for dissonance reduction. In: Theories of Cognitive Consistency: A Sourcebook, pp. 684-692.

Huber, J., Payne, J.W., Puto, C., 1982. Adding asymmetrically dominated alternatives: violations of regularity and the similarity hypothesis. J. Consumer Res. 9 (1), 90-98.

Iyengar, S.S., Lepper, M.R., 1999. Rethinking the value of choice: a cultural perspective on intrinsic motivation. J. Personal. Soc. Psychol. 76 (3), 349.

Konow, J., 2000. Fair shares: accountability and cognitive dissonance in allocation decisions. Am. Econ. Rev. 90 (4), $1072-1091$.

Lawler III, E.E., Kuleck Jr, W.J., Rhode, J.G., Sorensen, J.E., 1975. Job choice and post decision dissonance. Organ. Behav. Hum. Perform. 13 (1), 133-145.

Lombardi, M., 2009. Reason-based choice correspondences. Math. Soc. Sci. 57 (1), 58-66.

Loomes, G., Sugden, R., 1982. Regret theory: an alternative theory of rational choice under uncertainty. Econ. J. 92 (368), 805-824.

Mills, J., 1965. Avoidance of dissonant information.. J. Personal. Soc. Psychol. 2 (4), 589. 
Ok, E.A., Ortoleva, P., Riella, G., 2015. Revealed (p) reference theory. Am. Econ. Rev. 105 (1), 299-321.

Rabin, M., 1994. Cognitive dissonance and social change. J. Econ. Behav. Organ. 23 (2), 177-194.

Sarver, T., 2008. Anticipating regret: why fewer options may be better. Econometrica 76 (2), 263-305.

Savage, L.J., 1954. The Foundations of Statistics. Wiley Publications in Statistics.

Shafir, E., Simonson, I., Tversky, A., 1993. Reason-based choice. Cognition 49 (1-2), 11-36.

Simonson, I., 1989. Choice based on reasons: the case of attraction and compromise effects. J. Consumer Res. 16 (2), $158-174$.

Sleesman, D.J., Conlon, D.E., McNamara, G., Miles, J.E., 2012. Cleaning up the big muddy: a meta-analytic review of the determinants of escalation of commitment. Acad. Manag. J. 55 (3), 541-562.

Staw, B.M., 1976. Knee-deep in the big muddy: a study of escalating commitment to a chosen course of action. Organ. behav. Hum. Perform. 16 (1), $27-44$. Suzuki, T., 2017. Directives, expressives, and motivation. Theor. Econ. 12 (1), 175-210.

Yariv, L., 2002. I'll See It When I Believe It? A Simple Model of Cognitive Consistency.

Zanna, M.P., Aziza, C., 1976. On the interaction of repression-sensitization and attention in resolving cognitive dissonance. J. Personal. 44 (4), 577-593.

Zuckerman, M., Porac, J., Lathin, D., Deci, E.L., 1978. On the importance of self-determination for intrinsically-motivated behavior. Personal. Soc. Psychol. Bull. 4 (3), 443-446. 